\title{
PET imaging in adaptive radiotherapy of gastrointestinal tumours.
}

Philippe Bulens ${ }^{1,2,}{ }^{*}$, Melissa Thomas ${ }^{1,2,{ }^{*}}$, Christophe M. Deroose ${ }^{3,4}$, Karin Haustermans ${ }^{1,2}$

* Both authors contributed equally to this manuscript.

${ }^{1}$ KU Leuven - University of Leuven, Department of Oncology, B-3000 Leuven, Belgium

${ }^{2}$ University Hospitals Leuven, Department of Radiation Oncology, B-3000 Leuven, Belgium

${ }^{3}$ KU Leuven - University of Leuven, Department of Imaging \& Pathology, B-3000 Leuven, Belgium

${ }^{4}$ University Hospitals Leuven, Department of Nuclear Medicine, B-3000 Leuven, Belgium

5 Tables: Overview and main research question of studies in radiation treatment planning of oesophageal cancer (Table 1), pancreas cancer (Table 2), liver cancer (Table 3), rectal cancer (Table 4), anal cancer (Table 5)

1 Figure: Literature selection

1 Appendix: Detailed research strategy

\section{Corresponding author:}

Karin Haustermans

Herestraat 49

B-3000 Leuven, Belgium

Tel: +32 16346902

Fax: +3216347623

karin.haustermans@uzleuven.be 


\section{ABSTRACT}

Radiotherapy is the standard of care in the multimodality treatment of a variety of gastrointestinal (GI) tumours, such as oesophageal cancer, gastric cancer, rectal cancer and anal cancer. Additionally, radiotherapy has served as an alternative for surgery in patients with liver cancer, cancer of the biliary tract and pancreatic cancer. Positron-emission tomography (PET), generally in combination with computed tomography (CT), has an established role in the diagnosis, response assessment and (re-)staging of several GI tumours. However, the additional value of PET in adaptive radiotherapy, i.e. during the radiation treatment course and in the delineation process, is still unclear. When performed during radiotherapy, PET aims at assessing treatment-induced variations in functional tumour volumes to reduce the radiation target volume. Moreover, in the radiation treatment planning, tumour delineation could be more accurate by incorporating PET to identify the metabolic tumour volume. This review focuses on the additional value of PET for adaptive radiotherapy protocols as well as for the target volume adaptation for individualised treatment strategies in oesophageal, gastric, pancreatic, liver, biliary tract, rectal and anal neoplasms. 
KEY WORDS

PET, radiotherapy, adaptive, gastrointestinal tract 
$\underline{\text { PAGE COUNT (MANUSCRIPT) }}$

27

$\underline{\text { WORD COUNT (MANUSCRIPT) }}$

7216

$-4-$ 


\section{INTRODUCTION}

Over the past decades, the use of radiotherapy has been established as a standard of care in the multimodality treatment of a variety of gastrointestinal (GI) tumours, such as oesophageal cancer, gastric cancer, rectal cancer and anal cancer. Additionally, radiotherapy has served as an alternative for surgery in patients with liver cancer, cancer of the biliary tract and pancreatic cancer. For other GI tumours, such as cancer of the small and large bowel, the use of radiotherapy is limited.

The implementation of advanced radiotherapy techniques, such as intensity modulated radiotherapy (IMRT), volumetric modulated arc therapy (VMAT) and proton therapy paved the road towards individualised treatments with precision radiotherapy for patients with various GI tumours. This increased precision however comes at the cost of inadequate dose delivery when changes occur in the patient anatomy and the target volume during the course of radiotherapy. To overcome such suboptimal treatment, treatment plan adjustments using adaptive radiotherapy (ART) based on novel techniques such as in-room imaging with cone beam computed tomography (CBCT), automated contouring, tumour tracking technologies or hybrid machines such as magnetic resonance (MR) - linear accelerators, could be of interest.

Additionally, the non-invasive functional imaging technique positron-emission tomography (PET) could enable us to implement an ART protocol during (chemo)radiation to adapt the radiation target volume by providing biological information of the tumour that reflects the treatment-induced variation in anatomical and functional tumour volume. Modern nuclear medicine images are generated by hybrid cameras combining PET with MR or computed tomography $(\mathrm{CT})$. The PET information is superimposed on the radiological 
information, most often CT images. The most commonly used tracer in tumours of the GI tract, is $\left[{ }^{18} \mathrm{~F}\right]$-fluorodeoxyglucose $\left(\left[{ }^{18} \mathrm{~F}\right] \mathrm{FDG}\right)$, which accumulates in tissues with a high turnover of the glucose metabolism. Today $\left(\left[{ }^{18} \mathrm{~F}\right] \mathrm{FDG}\right.$ has an established role in the diagnosis, response assessment and (re-)staging of several GI tumours. Common methods of target volume segmentation for PET/CT images include visual judgement and automated contouring methods applying standardised uptake value (SUV) thresholds. Visual judgement relies solely on the visual discrimination of tumour boundaries, which can be subjective and can lead to interobserver bias. In addition, differences in scale settings contribute to variability. Threshold methods often use a fixed SUV or a certain percentage of the maximum SUV (SUV $\max$ ) as the threshold. These methods are limited with regard to variations in tumour size which affect image count levels due to partial volume effects, variable tumour to background activity, and heterogeneous tracer uptake in the tumour. Gradient-based methods use the maximum spatial gradient to detect boundaries between lesions and normal tissue, which is not affected by different imaging equipment, reconstruction algorithms and sphere diameter effects.

Unfortunately, data on the use of PET for ART strategies in Gl cancer during the course of treatment are scarce. PET however can also be used to adapt and improve the delineation of the target volume and organs at risk (OAR) before the start of radiotherapy. Furthermore, patients with Gl tumours display very heterogeneous tumour activity, indicating the need for individualised treatment strategies such as focal dose escalation or de-escalation, for which this biological imaging modality could be of use. Therefore, in this article we not only highlight the use of PET for ART protocols in oesophageal, gastric, pancreatic, liver, biliary tract, rectal and anal neoplasms, but also review the additional value of PET for target volume adaptation for individualised treatment strategies. 


\section{EVIDENCE ACQUISITION}

The MEDLINE database was searched for the terms ("Radiotherapy"[Mesh] AND "Positron-Emission Tomography"[Mesh] AND one of the site-specific keywords: "Esophageal Neoplasms"[Mesh], "Stomach Neoplasms"[Mesh], "Pancreatic Neoplasms"[Mesh], "Liver Neoplasms"[Mesh], "Biliary Tract Neoplasms"[Mesh], “Colonic Neoplasms"[Mesh], "Rectal Neoplasms"[Mesh] or "Anus Neoplasms"[Mesh]) (February 2018)1. The detailed search strings are available in the supplementary material provided with this review paper (Appendix 1). Only papers published in Dutch, English, French and German were included.

These initial searches yielded respectively 490 articles for oesophageal neoplasms, 89 articles for stomach neoplasms, 192 articles for pancreatic neoplasms, 372 articles for liver neoplasms, 46 articles for biliary tract neoplasms, 77 articles for colonic neoplasms, 373 articles for rectal neoplasms and 71 articles for anus neoplasms.

All titles and abstracts were screened and only studies reporting on the role of positron emission tomography (PET) in adaptive radiotherapy or individualised treatment strategies were retained. Reviews, general overview articles, comments, congress abstracts and papers reporting on the role of PET for disease staging, response outcome and prognosis were excluded. To identify additional relevant studies, the reference list of the retrieved studies was checked manually. In total, 27 relevant papers were identified for oesophageal neoplasms, 1 for gastric neoplasms, 9 for pancreatic neoplasms, 6 for liver neoplasms, 1 for biliary tract neoplasms, none for colonic neoplasms, 15 for rectal neoplasms and 12 for anus neoplasms. Literature selection results are depicted in Fig. 1. 


\section{EVIDENCE SYNTHESIS}

\section{Oesophageal cancer}

An adaptive treatment strategy is uncommon in radiotherapy for oesophageal cancer. However, during the course of radiotherapy, intra- and interfractional anatomical changes are observed due to respiratory motion and abdominal filling, especially for distal tumours ${ }^{2,3}$. In addition to these intra- and interfractional anatomical changes, also tumour shrinkage plays a role. An ART strategy using $\mathrm{CBCT}$ imaging or replanning $\mathrm{CT}$ scan during treatment was studied in the past ${ }^{4,5}$. Only two retrospective planning studies investigated the value of $\left[{ }^{18} \mathrm{~F}\right] \mathrm{FDG}-\mathrm{PET} / \mathrm{CT}$ during chemoradiotherapy for dose escalation in patients with oesophageal cancer. The rationale behind these studies is the high incidence of loco-regional failures and persistent disease, mainly in patients treated with definitive chemoradiation. Although dose escalation, in an attempt to maximise local control, has not been proven successful in the past ${ }^{6}$, the progress made in medical imaging and radiotherapy techniques led to a renewal of the interest in dose escalation for oesophageal cancer. The reduced target volume during chemoradiation based on PET-imaging could allow for escalation of the dose without hampering the normal tissue tolerance. In the study of Nkhali et al. ${ }^{7}$, ten patients with squamous cell carcinoma (SCC) underwent an $\left[{ }^{18} \mathrm{~F}\right] \mathrm{FDG}-\mathrm{PET} / \mathrm{CT}$ scan before and on day 21 after start of radiotherapy. Four different radiotherapy plans were calculated using a prescription dose of either 50 Gy or 66 Gy to the CTV, based on the GTV of the pretreatment $\left[{ }^{18} \mathrm{~F}\right]$ FDG-PET/CT scan, or based on the GTV of the $\left[{ }^{18} \mathrm{~F}\right] \mathrm{FDG}-\mathrm{PET} / \mathrm{CT}$ on day 21. A SUV threshold was chosen after visual inspection by a radiation oncologist and a nuclear medicine physician. The median [ $\left.{ }^{18} \mathrm{~F}\right]$ FDG-PET/CT-based GTV significantly decreased 
between the two PETs. However, in contrast to the large reduction in PTV based on the $\left[{ }^{18} \mathrm{~F}\right] \mathrm{FDG}-\mathrm{PET} / \mathrm{CT}$ on day 21 , the median reduction in OAR irradiation was moderate. Nevertheless, this was statistically significant when increasing the total dose to $66 \mathrm{~Gy}$. Seol et al. ${ }^{8}$ investigated the efficacy of visual interpretation of $\left[{ }^{18} \mathrm{~F}\right]$ FDG-PET/CT for a boost plan of 20 Gy after delivery of the initial $40 \mathrm{~Gy}$. Thirty-three patients underwent an $\left[{ }^{18} \mathrm{~F}\right] \mathrm{FDG}-\mathrm{PET} / \mathrm{CT}$ scan both before the treatment and after the delivery of 40 Gy. GTVs were separately defined using CT scan alone or using $\left[{ }^{18}\right.$ F]FDG-PET/CT combined information and subsequently compared using an index of conformity $(\mathrm{Cl})$. In 18 patients, the $\left[{ }^{18} \mathrm{~F}\right] \mathrm{FDG}$ PET/CT-based GTV was at least 5\% larger than the CT-based GTV; in eight patients, it was at least 5\% smaller. Twenty-three patients (77\%) achieved a metabolic response with a tumour SUV $_{\max }$ reduction of $>35 \%$ and there was significant decrease in metabolic tumour volume (MTV) and total glycolytic activity (TGA). These findings resulted in target volume reductions in the radiotherapy boost plans. However, the impact of the different radiotherapy plans on dose to OAR was not assessed.

In contrast to the role of PET in the diagnosis and (re-)staging and response prediction after neoadjuvant treatment, its use for radiotherapy target volume delineation and radiotherapy planning is still debated and widely studied (table 1). A study of Vrieze et al. ${ }^{9}$ focused on the detection of pathologic lymph nodes to determine the additional value of $\left[{ }^{18} \mathrm{~F}\right]$ FDG-PET in optimising the CTV. They prospectively included 30 patients with advanced oesophageal cancer. In six patients, eight positive lymph nodes were identified on $\left[{ }^{18} \mathrm{~F}\right] \mathrm{FDG}$ PET alone. In three of these patients the target volume would be enlarged, suggesting that the irradiated volume based on a positive $\left[{ }^{18} \mathrm{~F}\right] \mathrm{FDG}-\mathrm{PET}$ in a region without suspected lymph nodes on CT and/or EUS should be considered. By contrast, in eight patients, nine positive lymph nodes were identified only on CT scan and EUS, indicating that the irradiated volume 
should not be reduced based on a negative $\left[{ }^{18} \mathrm{~F}\right] \mathrm{FDG}-\mathrm{PET}$. However, the lack of histological confirmation of discordant findings was the major shortcoming of the study. Another study of Konski et al. ${ }^{10}$ focussed on the use of $\left[{ }^{18} \mathrm{~F}\right] \mathrm{FDG}$-PET/CT in the determination of the tumour length in 25 patients. Compared to CT scan alone, $\left[{ }^{18} \mathrm{~F}\right]$ FDG-PET resulted in a significant reduction in the mean length of the primary tumour $(5.4 \mathrm{~cm}$ vs. $6.77 \mathrm{~cm})$. Similar results were obtained by a retrospective study of Foley et. ${ }^{11}$ al on 160 patients. Compared to EUS, considerd to assess more accurately local disease due to its superior contrast and spatial resolution, $\left[{ }^{18} \mathrm{~F}\right] \mathrm{FDG}-\mathrm{PET} / \mathrm{CT}$ underestimated the length of the tumour $(6.4 \mathrm{~cm}$ vs. $8.0 \mathrm{~cm})$, hence inducing a risk of a geographical miss in $38.1 \%$ of 61 patients. Besides the tumour length, Moureau-Zabotto et al. ${ }^{12}$ defined and compared the GTVs among 34 oesophageal cancer patients based on CT scan alone and $\left[{ }^{18} \mathrm{~F}\right] \mathrm{FDG}-\mathrm{PET}$. The tumour length and GTV delineation decreased by fusion of CT and [ $\left.{ }^{18} \mathrm{~F}\right]$ FDG-PET images in respectively 12 (35\%) and $12(35 \%)$ patients and increased in respectively $12(35 \%)$ and seven (21\%) patients. These modifications in GTV were mainly due to a reduction in tumour length or the detection of involved lymph nodes by $\left[{ }^{18} \mathrm{~F}\right] \mathrm{FDG}-\mathrm{PET}$, affecting the PTV in 18 patients (53\%). [ $\left.{ }^{18} \mathrm{~F}\right] \mathrm{FDG}-\mathrm{PET}-$ based radiotherapy planning led to both increase and decrease of lung and heart doses. Similarly, in a prospective study of Leong et al. ${ }^{13,34}$ on 16 patients, the GTV based on CT scan alone excluded PET-avid disease in 11 patients (69\%), and, assuming that $\left[{ }^{18} \mathrm{~F}\right] \mathrm{FDG}$-PET is the gold standard, in five patients (31\%) this would have resulted in a geographic miss of tumour, mainly due to differences in longitudinal direction. In six patients (38\%), the coverage of the $\left[{ }^{18} \mathrm{~F}\right] \mathrm{FDG}$-PET/CT-based PTV was considered to be inadequate if the treatment plans were based on the CT scan alone, without clinically significant differences in the radiation dose to OAR. Gondi et al. ${ }^{14}$ investigated the impact of integrated $\left[{ }^{18} \mathrm{~F}\right] \mathrm{FDG}$ $\mathrm{PET} / \mathrm{CT}$ in radiotherapy planning in 16 patients with oesophageal cancer, using a $\mathrm{Cl}$ to 
quantify size differences as well as three-dimensional overlap in GTV obtained using CT scan alone or $\left[{ }^{18} \mathrm{~F}\right] \mathrm{FDG}-\mathrm{PET} / \mathrm{CT}$. In 10 patients (62.5\%), the addition of the $\left[{ }^{18} \mathrm{~F}\right] \mathrm{FDG}-\mathrm{PET}$ data led to a smaller GTV, and the mean conformity was 0.46 (range $0.13-0.8$ ). In the study of Muijs et al. ${ }^{15}$ on 21 patients with oesophageal cancer treated with a three-dimensional conformal radiation therapy (3D-CRT) plan to a total dose of $50.4 \mathrm{~Gy}$, the additional use of $\left[{ }^{18} \mathrm{~F}\right] \mathrm{FDG}$ PET/CT led to a decrease or increase of the CT-based GTV with at least $10 \%$ in nine $(43 \%)$ and four (19\%) patients respectively. An $\left[{ }^{18} \mathrm{~F}\right] \mathrm{FDG}-\mathrm{PET} / \mathrm{CT}$-based PTV was inadequately covered by CT-based radiotherapy plans in 8 patients (38\%), potentially resulting in underdosage of the tumour. Similar to the previously described studies, adjustments regarding the GTV were mainly seen at the cranio-caudal extent of the tumour. Furthermore, treatment plan modifications significantly changed the radiation dose to OAR thereby affecting the risk of developing late symptomatic radiation pneumonitis and cardiac mortality. Nineteen patients were included in a retrospective planning study of le Grange et al. ${ }^{16}$. Two sets of GTV were delineated using the $\left[{ }^{18} \mathrm{~F}\right] \mathrm{FDG}-\mathrm{PET} / \mathrm{CT}$ data sets and the planning CT scan. GTVs based on $\left[{ }^{18} \mathrm{~F}\right] \mathrm{FDG}-\mathrm{PET} / \mathrm{CT}$, with nodal volumes included, were larger than CTbased GTVs in 12 patients, smaller in six and equal in one. Previously undetected locoregional nodal involvement was seen on $\left[{ }^{18} \mathrm{~F}\right] \mathrm{FDG}-\mathrm{PET} / \mathrm{CT}$ in three cases and included in the PTV. Radiotherapy plans were made for both sets of PTV in 16 patients. In nine cases, the $\left[{ }^{18} \mathrm{~F}\right]$ FDG-PET/CT-based PTV was inadequately covered by the CT-based radiation plan, raising concern about potential for geographical miss.

Several studies investigated the validity of different target volume delineation methods based on PET, resulting in a variety of recommendations. Thomas et al. ${ }^{17}$ compared the tumour volume of 20 patients as delineated on $\left[{ }^{18} \mathrm{~F}\right] \mathrm{FDG}-\mathrm{PET} / \mathrm{CT}$ after either rigid or nonrigid registration, with a reference tumour volume delineated on CT with endoscopy-guided 
clipping of the tumour. A large variability between tumour segmentation algorithms was found but no $\left[{ }^{18} \mathrm{~F}\right]$ FDG-PET-based segmentation algorithm performed better than a CT-based delineation without clips. The best correlation for semi-automatic delineation was found between the GTV based on clips and the gradient-based algorithm. For the analysis of tumour length, no homogeneous correlation was found. Similar results were obtained by Niyazi et al. ${ }^{18}$, retrospectively comparing manually delineated GTV on CT scan, taking into account the results of diagnostic PET imaging, and five different automatically generated ${ }^{[18}$ F]FDG-PET/CT-based MTV in 20 patients. Eight patients had lung cancer, five oesophageal cancer and seven cancer of the pelvic region. The $\mathrm{Cl}$ and the ratio intersection between GTV/MTV and GTV volumes were computed. Results showed an overall low concordance between manually derived GTVs and automatically segmented $\left[{ }^{18}\right.$ F]FDG-PET/CT-based MTV. Hong et al. ${ }^{19}$ evaluated the role of $\left[{ }^{18} \mathrm{~F}\right] \mathrm{FDG}-\mathrm{PET} / \mathrm{CT}$ in target volume definition in twenty-five patients using a manual and semi-automated technique, compared to CT scan alone. When comparing CT-based GTVs to manually defined $\left[{ }^{18}\right.$ F]FDG-PET/CT-based GTVs, the use of PET changed the GTV in 21 patients (84\%). In 12 patients (48\%) the superior or inferior extent (or both) of the primary tumour differed by $1-2 \mathrm{~cm}$ (i.e. minor); in 9 patients (36\%) the craniocaudal extent differed more than $2 \mathrm{~cm}$ or involvement of different nodal regions were identified beyond the longitudinal extent of the primary tumour (i.e. major). The use of the semi-automated delineation changed the manual PET length in 14 patients (56\%): 8 (32\%) minor and 6 (34\%) major differences. In comparison to a CT-based GTV delineation, focussing on the radial extent of the tumour, Vali et al. ${ }^{20}$ found that the use of an SUV threshold of 2.5 had the best performance of 11 different SUV-based approaches for $\left[{ }^{18}\right.$ F]FDG-PET/CT-based delineation of the MTV in 22 patients with oesophageal cancer. In contrast, the signal-to-background ratio (SBR) was the most optimal automatic segmentation 
method found in a retrospective study of Encaoua et al. ${ }^{21}$ in 58 patients. The CT-based GTV was significantly longer than the GTV based on SBR, resulting in lower doses to the lungs, heart, and spinal cord when radiotherapy plans were based on the SBR-based PTV.

In addition to the adaptation of the initial target volume, the use of $\left[{ }^{18} \mathrm{~F}\right]$ FDG-PET has also been investigated for the delivery of a selective radiotherapy boost. Yu et al. ${ }^{22}$ found that a simultaneous integrated boost (SIB) of maximum 70 Gy to the high $\left[{ }^{18} \mathrm{~F}\right] \mathrm{FDG}$-uptakeregion of the GTV could be delivered safely, although no assessment of late toxicity and long-term outcome was done. On the other hand, Ma et al. ${ }^{23}$ showed that a sequential boost up to 63-70 Gy in 52 patients with non-complete metabolic response after $50.4 \mathrm{~Gy}$, improved complete response rate, two-year overall survival and local control, although no details were provided on the use of [ $\left.{ }^{18} \mathrm{~F}\right]$ FDG-PET in the delineation process.

Several factors need to be accounted for when using PET for tumour delineation. First, intra- and/or interobserver variability needs to be minimised. Vesprini et al. ${ }^{24}$ showed, in a study of ten patients, significantly less intra- and interobserver variability for GTV, tumour length and volume overlap when delineating based on $\left[{ }^{18} \mathrm{~F}\right] \mathrm{FDG}-\mathrm{PET} / \mathrm{CT}$ in comparison to a CT-based method. Most frequently, the inferior or gastric extension was adapted based on $\left.{ }^{18} \mathrm{~F}\right] \mathrm{FDG}-\mathrm{PET} / \mathrm{CT}$. In contrast to Vesprini et al., Schreurs et al. ${ }^{25}$ did not observe an improvement in interobserver variability by the use of $\left[{ }^{18} \mathrm{~F}\right] \mathrm{FDG}-\mathrm{PET} / \mathrm{CT}$ in 28 patients. However, incorporation of $\left[{ }^{18} \mathrm{~F}\right]$ FDG-PET/CT modified the tumour delineation in 17 patients $(61 \%)$, with a rate of $11 \%$ of the volume of the $\left[{ }^{18} \mathrm{~F}\right] \mathrm{FDG}-\mathrm{PET} / \mathrm{CT}$-based CTVs situated outside the target volume based on CT scan alone.

Second, although the addition of PET/CT resulted in altered target volume delineation, these modifications need to be validated by a gold standard which in this case is the pathology examination of the resection specimen. Mamede et al. ${ }^{26}$ were the first to 
retrospectively report a positive correlation between $\left[{ }^{18} \mathrm{~F}\right] \mathrm{FDG}-\mathrm{PET}$-based tumour lengths, estimated for different SUV thresholds, and the pathological findings on resection specimens of 17 patients after oesophagectomy without neoadjuvant treatment. Similar results were found by a prospective study of Zhong et al. ${ }^{27}$ in 36 patients with a SCC. The $\left[{ }^{18} \mathrm{~F}\right] \mathrm{FDG}-\mathrm{PET}-$ based tumour length correlated well with the pathological tumour length, for three initial threshold methods. After postoperative delineation of the GTV using various percentages of SUV $V_{\max }$, a cut-off of SUV 2.5 seemed the most approximate to the pathological tumour length. In contrast, Yu et al. ${ }^{28}$ found no optimal SUV threshold for the correlation between pathological tumour length and overlay, delineated on fusion images of pre- and postsurgical scan, and four different automatic segmentation methods on $\left[{ }^{18} \mathrm{~F}\right] \mathrm{FDG}-\mathrm{PET} / \mathrm{CT}$ in 16 patients with a SCC.

Third, despite the fact that most trials studied the use of $\left[{ }^{18} \mathrm{~F}\right] \mathrm{FDG}-\mathrm{PET}$, two studies investigated the use of another tracer, $\left[{ }^{18} \mathrm{~F}\right]$-fluorothymidine $\left(\left[{ }^{18} \mathrm{~F}\right] \mathrm{FLT}\right)$. Compared to CT scan alone, Zhang et al. ${ }^{29}$ found that the tumour length based on a gradient-based segmentation method using $\left[{ }^{18} \mathrm{~F}\right] \mathrm{FLT}-\mathrm{PET}$ was the most consistent with pathological specimens in ten patients with a SCC. Since the GTV based on the gradient-based segmentation was smaller than the CT-based GTV, the 3D-CRT treatment plan of the first mentioned GTV resulted in significantly lower dose to the OAR. On the other hand, Han et al. ${ }^{30}$ compared $\left[{ }^{18} \mathrm{~F}\right] \mathrm{FDG}$ $\mathrm{PET} / \mathrm{CT}$ and $\left[{ }^{18} \mathrm{~F}\right] \mathrm{FLT}-\mathrm{PET} / \mathrm{CT}$ in a group of 22 patients. After delineation of the GTV using various percentages of SUV $V_{\text {max }}$, a cut-off of 1.4 on [ $\left.{ }^{18} \mathrm{~F}\right] \mathrm{FLT}-\mathrm{PET} / \mathrm{CT}$ and an SUV cut-off of 2.5 on $\left[{ }^{18} \mathrm{~F}\right] \mathrm{FDG}-\mathrm{PET} / \mathrm{CT}$ provided the closest estimation of the postoperative pathological GTV length. Furthermore, radiotherapy plans using the $\left[{ }^{18} \mathrm{~F}\right] \mathrm{FLT}$ - and $\left[{ }^{18} \mathrm{~F}\right] \mathrm{FDG}-\mathrm{PET} / \mathrm{CT}$ optimal threshold contouring target volumes showed a significantly lower mean lung and heart dose, 
bilateral lung volume receiving $\geq 5, \geq 10, \geq 30, \geq 40$, and $\geq 50$ Gy and heart volume receiving $\geq 30$ Gy when $\left[{ }^{18} \mathrm{~F}\right] \mathrm{FLT}-\mathrm{PET} / \mathrm{CT}$-based planning was used.

Fourth, oesophageal tumours display significant tumour motion during treatment. Nevertheless, most PET-scans are acquired in a free breathing state and thus the PET images are an average obtained during several respiratory cycles. Therefore, FDG quantification, tumour margin definition and detection of smaller tumours can be improved by the application of respiratory gating techniques or 4D-PET. Three studies by Guo et $\mathrm{al}^{35-37}$, evaluating the implementation of a 4D-planning-CT scan and a $3 \mathrm{D}-\left[{ }^{18} \mathrm{~F}\right] \mathrm{FDG}-\mathrm{PET} / \mathrm{CT}$ in the radiation treatment planning of oesophageal cancer, have reported that this combination of techniques has an impact on target definition. However, $\left[{ }^{18} \mathrm{~F}\right] \mathrm{FDG}-\mathrm{PET} / \mathrm{CT}$-based target volumes did not correspond well with 4D-CT-based target volumes, indicating the need for 4D-PET/CT. Wang et al. ${ }^{31}$ were the first to report prospectively the feasibility of 4D-[ $\left.{ }^{18} \mathrm{~F}\right] \mathrm{FDG}$ $\mathrm{PET} / \mathrm{CT}$ in radiotherapy planning in 12 patients with oesophageal cancer, by comparing the CT-based GTV and 4D-[ $\left.{ }^{18} \mathrm{~F}\right]$ FDG-PET/CT-based GTV, using eight different threshold methods. The PET-based GTV using a threshold setting of $20 \%$ of SUV $\max$ or SUV of 2.5 correlated well with tumour length, the $\mathrm{Cl}$ and the VR. Scarsbook et al. ${ }^{32}$ found no significant differences between the volume and tumour lengths on 4D-CT, 4D-CT with co-registered 3D-[ $\left.{ }^{18} \mathrm{~F}\right] \mathrm{FDG}$ PET and 4D-[ $\left.{ }^{18} \mathrm{~F}\right]$ FDG-PET/CT in seven patients with an oesophageal carcinoma. Furthermore, there was no difference between target volume positional metrics defined on each of the different CT and PET combinations. However, the percentage overlap analysis demonstrated that approximately $20 \%$ of the PTV based on the combination of 3D-[ $\left.{ }^{18} \mathrm{~F}\right] \mathrm{FDG}-\mathrm{PET}$ and $4 \mathrm{D}-\mathrm{CT}$ and the PTV based on 4D-[ $\left.{ }^{18} \mathrm{~F}\right] \mathrm{FDG}-\mathrm{PET} / \mathrm{CT}$ were not included in the PTV, theoretically leading to undercoverage of the target volume and a potential geometric miss. 
Based on all aforementioned studies, there is a potential role for $\left[{ }^{18} \mathrm{~F}\right] \mathrm{FDG}-\mathrm{PET} / \mathrm{CT}$ in radiation treatment planning. However, to date, only one study assessed the clinical validation of $\left[{ }^{18} \mathrm{~F}\right] \mathrm{FDG}-\mathrm{PET} / \mathrm{CT}$ in the radiation treatment planning by determining the proportion of loco-regional recurrences that could have been prevented if radiation treatment planning for oesophageal cancer was based on $\left[{ }^{18} \mathrm{~F}\right] \mathrm{FDG}-\mathrm{PET} / \mathrm{CT}$ instead of $\mathrm{CT}$ scan. In a small prospective observational study of Muijs et al. ${ }^{33}, 90$ patients with oesophageal cancer underwent a planning $\left[{ }^{18} \mathrm{~F}\right] \mathrm{FDG}-\mathrm{PET} / \mathrm{CT}$, but were treated according to the CT-based treatment plans. After the end of the treatment, the original GTV and CTV were adjusted to the findings on $\left[{ }^{18} \mathrm{~F}\right] \mathrm{FDG}-\mathrm{PET} / \mathrm{CT}$. The authors noted that the $\left[{ }^{18} \mathrm{~F}\right] \mathrm{FDG}$ PET/CT-based GTV could be larger or smaller than the CT-based GTV. The proportion of the GTV based on $\left[{ }^{18} \mathrm{~F}\right] \mathrm{FDG}-\mathrm{PET} / \mathrm{CT}$ which could be missed with CT-only based GTV was more than 5\% in 32 patients. Primary endpoint was loco-regional recurrence, which was seen in 10 patients (11\%). Most of the recurrences were located within the irradiated volume or far from both the CT-based and $\left[{ }^{18} \mathrm{~F}\right] \mathrm{FDG}-\mathrm{PET} / \mathrm{CT}$-based CTV. As a consequence, they stated that there were no loco-regional recurrences after CT-based radiotherapy that could have been prevented by $\left[{ }^{18} \mathrm{~F}\right]$ FDG-PET/CT guided treatment.

In conclusion, the role of PET in oesophageal cancer during radiotherapy and in the radiation treatment planning is not yet well established, given the variety of results described in previous trials. However, PET has proven to be useful in the diagnosis and staging of oesophageal cancer patients, which can lead to the adaptation of the radiation treatment in the identification of involved lymph nodes and subsequent modification of a CT-based treatment plan. 


\section{Gastric cancer}

The role of radiotherapy in gastric cancer remains unclear. Therefore, data on the use of PET/CT in ART and radiation treatment planning are scarce. Even in the staging of gastric cancers, the role of PET/CT is not well established because of the low detection rate due to the low tracer accumulation in diffuse and mucinous tumour types and signet-ring cell carcinoma, which are frequent types of gastric cancer ${ }^{38}$. We found no studies regarding the role of PET/CT during radiotherapy. We identified one retrospective study of Dębiec et al. ${ }^{39}$ investigating the use of $\left[{ }^{18} \mathrm{~F}\right] \mathrm{FDG}-\mathrm{PET} / \mathrm{CT}$ in the delineation process in 24 patients with locally advanced unresectable or inoperable gastric cancer treated with radical chemoradiotherapy or radiotherapy alone. The GTV based on manual delineation on $\left[{ }^{18} \mathrm{~F}\right] \mathrm{FDG}-\mathrm{PET} / \mathrm{CT}$ was smaller or larger than the CT-based GTV in 11 (46\%) and 13 (54\%) patients respectively. After comparing with MTVs using different threshold levels (SUV $\geq 2.5$, SUV $\geq$ mean liver SUV plus two standard deviations and SUV $\geq 10 / 20 / 30 / 40 / 50 / 60 / 70 \%$ of SUV $_{\max }$ ), the highest correlation degree between the CT-based GTV and [ $\left.{ }^{18} \mathrm{~F}\right]$ FDG-PET-based GTV was seen with the manual delineation. Based on this study, no conclusion on the use of $\left[{ }^{18} \mathrm{~F}\right] \mathrm{FDG}-\mathrm{PET} / \mathrm{CT}$ in the delineation process of gastric cancer can be drawn. 


\section{Pancreatic cancer}

Radiotherapy can be used to treat borderline resectable pancreatic cancer as part of a neoadjuvant chemoradiation treatment ${ }^{40}$. Furthermore, in patients with locally advanced pancreatic carcinoma, definitive chemoradiotherapy can be an alternative for chemotherapy alone $^{41}$. To correct for interfraction variations during these radiation treatments, online adaptive correction schemes have been investigated for the treatment of pancreatic cancer. Previous research mainly focused on the use of daily $\mathrm{CT}^{42-44}$ or even MRI for this purpose ${ }^{44}$. Unlike CT and MRI, to date, the use of PET to adapt the radiotherapy plan on a daily basis has not been investigated. On the other hand, there are several papers reporting on the usefulness of PET imaging for the optimisation of target volume delineation ${ }^{45-51}$ and the delivery of a radiotherapy boost ${ }^{52,53}$ to improve the response outcome for patients with pancreatic cancer treated with radiotherapy (table 2).

Significant differences exist between various imaging techniques used for GTV definition ${ }^{45}$. A study on 14 patients with locally advanced pancreatic cancer showed that in 5 patients, the GTV needed to be adapted based on the information acquired with [ $\left.{ }^{18} \mathrm{~F}\right] \mathrm{FDG}$ PET with additional lymph node metastases or extension of the primary tumour beyond the region defined by $\mathrm{CT}^{46}$. The resulting GTV was significantly larger than the initial GTV based on CT only (104.5 $\mathrm{cm}^{3}$ vs. $\left.92.5 \mathrm{~cm}^{3}\right)$ but this did not result in significant dose differences to the surrounding organs at risk. Based on these findings, the same group initiated a phase II trial in which they investigate the effect of using an $\left[{ }^{18} \mathrm{~F}\right] \mathrm{FDG}-\mathrm{PET} / \mathrm{CT}$-based GTV. Preliminary analyses of the first 30 of 120 patients in this trial showed that the $\left[{ }^{18} \mathrm{~F}\right] \mathrm{FDG}$-PET/CT-defined GTV size has potential to predict the outcome of patients with locally advanced pancreatic cancer treated with chemoradiotherapy ${ }^{47}$. Whereas Topkan et al. ${ }^{46}$ found the mean GTV to 
be increased when combining information of both CT and $\left[{ }^{18} \mathrm{~F}\right]$ FDG-PET, Li et al. ${ }^{48}$ found the mean GTV to be significantly smaller when using an $\left[{ }^{18}\right.$ F]FDG-PET/CT-based target delineation method vs. a CT-based method $\left(49.3 \mathrm{~cm}^{3}\right.$ vs. $64.1 \mathrm{~cm}^{3}$ respectively). This difference could be attributed to the differences in scale settings for the PET images in both studies. Although $\left[{ }^{18} \mathrm{~F}\right] \mathrm{FDG}-\mathrm{PET}$ seems useful for target volume definition in pancreatic cancer, it remains difficult to implement as a pancreatic tumour displays significant motion variability during respiration. Therefore, Kishi and colleagues ${ }^{49}$ investigated in 14 patients whether respiratory-gated PET (4D-PET) could improve the radiation treatment planning for pancreatic cancer. In this study, on average the 4D [ $\left.{ }^{18} \mathrm{~F}\right] \mathrm{FDG}$-avid tumour volumes were 2fold smaller than the target volumes defined on non-respiratory-gated $\left[{ }^{18} \mathrm{~F}\right] \mathrm{FDG}-\mathrm{PET}$. Therefore, 4D $\left[{ }^{18} \mathrm{~F}\right]$ FDG-PET could be used to improve the accuracy or to reduce the normal tissue irradiation compared with conventional ungated $\left[{ }^{18} \mathrm{~F}\right]$ FDG-PET. Finally, in addition to the use of $\left[{ }^{18} \mathrm{~F}\right] \mathrm{FDG}$ as a tracer for target volume definition, also the use of other tracers has been investigated. In an exploratory analysis of 9 patients, Pretz et al. ${ }^{50}$ found the tracer [18F]FLT to improve interobserver concordance when delineating the GTV. Although its use for this purpose has not yet been explored, the hypoxia tracer [18F]-3-Fluoro-2-(4-((2-nitro1H-imidazol-1-yl)methyl)-1H-1,2,3-triazol-1-yl)propan-1-ol ([18 F]HX4) could be a promising tool for radiation therapy planning, as demonstrated by the high reproducibility when measuring the amount and location of elevated $\left[{ }^{18} \mathrm{~F}\right]-\mathrm{HX} 4{ }^{51}$.

Several authors have highlighted the potential of PET imaging for focal boosting strategies in the radiation treatment for locally advanced pancreatic cancer. In a set of 17 patients, Wilson et al. ${ }^{52}$ showed that the maximum SUV before chemoradiation could predict regions of residual metabolic activity after this treatment, which could be used to define a biological target volume for an additional boost dose. A revision of their institutional results 
for the chemoradiation treatment of borderline resectable pancreatic cancer by Huang et al. ${ }^{53}$ revealed that in 25 of 28 patients a dose escalation protocol using a simultaneous integrated boost on the GTV as defined on $\left[{ }^{18} \mathrm{~F}\right] \mathrm{FDG}-\mathrm{PET} / \mathrm{CT}$ could be completed with acceptable toxicity and an achieved negative margin in 95\% of cases undergoing subsequent pancreatectomy. Notwithstanding both studies hint to a benefit when using PET-based boost strategies, no solid evidence yet exists to implement such strategies in the current treatment landscape of pancreatic cancer. 


\section{Biliary tract cancer}

Chemoradiotherapy can be an option to treat unresectable non-metastatic extrahepatic cholangiocarcinoma $(\mathrm{EHCC})^{54}$. Although no papers were retrieved on the use of PET imaging to adapt treatment during the course of radiotherapy, Onal et al. ${ }^{55}$ discussed the benefit of $\left[{ }^{18} \mathrm{~F}\right] \mathrm{FDG}-\mathrm{PET} / \mathrm{CT}$-based target volume contouring for radiation treatment planning. In their study on 15 patients, the authors showed a significant decrease in the GTV and PTV in comparison to CT-based contouring, resulting in reduced liver doses and a nearsignificant decrease in the dose to the right kidney. Furthermore, a significant mismatch of GTV and PTV between CT- and [ ${ }^{18}$ F]FDG-PET/CT-based plans was observed, which could negatively impact local control and survival in EHCC patients, given the dose-response relationship for overall survival ${ }^{56}$. Therefore, adaptation of the radiation treatment using ${ }^{18}$ F]FDG-PET could be of clinical use in patients with EHCC, although further investigation to confirm these results is needed. 


\section{Liver cancer}

Malignant lesions in the liver include hepatocellular carcinoma (HCC), intrahepatic cholangiocarcinoma and hepatic metastases. Although surgery is the standard local treatment for these lesions, most patients are not surgical candidates. Therefore, there is growing interest in less invasive options such as radiofrequency ablation (RFA) and radiotherapy, including stereotactic body radiation therapy (SBRT). Additionally, transarterial radioembolization (TARE) and chemoembolization (TACE) are gaining in popularity.

The implementation of PET/CT in radiotherapy planning of the liver suffers from image degradation due to respiratory motion of the target and the lack of SUV threshold standardisation. This is probably the reason why we found no studies regarding the role of PET for treatment adaptation during external beam radiotherapy (EBRT). Only few studies investigated the use of [18]FDG-PET/CT in the delineation process and treatment planning of liver radiotherapy (table 3). Parlak et al. ${ }^{57}$ performed a dosimetric study in 38 patients with colorectal liver metastasis treated with radiotherapy to a total dose of $60 \mathrm{~Gy}$ in two fractions daily of $1.5 \mathrm{~Gy}$. The GTV changed in 31 patients (81.6\%) after delineation on [ $\left.{ }^{18} \mathrm{~F}\right]$ FDG$\mathrm{PET} / \mathrm{CT}$, taking a threshold of SUV of at least $10 \%$ greater than normal liver parenchyma, with a significant increase in 25 patients $(65.8 \%)$ and a decrease in six patients $(15.8 \%)$. However, there was no clinically relevant change in dose to OAR. In a study by Steffen et al. ${ }^{58}$, the value of $\left[{ }^{18} \mathrm{~F}\right] \mathrm{FDG}-\mathrm{PET} / \mathrm{CT}$ for radiation treatment planning was assessed in 19 patients with colorectal liver metastasis that received high-dose-rate brachytherapy for 38 lesions. Adding the $\left.{ }^{18} \mathrm{~F}\right] \mathrm{FDG}-\mathrm{PET} / \mathrm{CT}$ information to the conventional planning $\mathrm{CT}$ scan resulted in a change in CTV in $84 \%$ of the lesions, with an increase in 15 cases and a decrease 
in six cases. The median $\left[{ }^{18} \mathrm{~F}\right] \mathrm{FDG}-\mathrm{PET} / \mathrm{CT}$-based CTV was significantly larger than the CTbased CTV, resulting in a greater radiation dose to normal liver parenchyma when assuming a satisfactory dose coverage of the $\left[{ }^{18} \mathrm{~F}\right] \mathrm{FDG}-\mathrm{PET} / \mathrm{CT}$-based CTV. Additionally, they observed a significantly higher rate of early local progression in those with additional [ $\left.{ }^{18} \mathrm{~F}\right] \mathrm{FDG}$-PET/CTpositive regions missed by the CT-based dose coverage. In a study of Bundschuh et al. ${ }^{59}$ in 14 patients with 16 liver metastasis scheduled for SBRT, the PET-based GTVs were $13.8 \%$ larger than in MRI, with a more pronounced difference in patients with a previous local treatment, indicating the need of $\left[{ }^{18} \mathrm{~F}\right] \mathrm{FDG}-\mathrm{PET} / \mathrm{CT}$ to distinguish vital tumour tissue and scar tissue in these patients. Furthermore, $\left[{ }^{18} \mathrm{~F}\right]$ FDG-PET/CT reduced the interobserver variability significantly. The use of semi-automatic threshold-based lesion segmentation in PET data did not provide satisfying results. A respiratory-gated PET allowed superior image co-registration with MR images compared to non-gated PET. Similarly, Riou et al. ${ }^{60}$ found a more appropriate evaluation of the internal target volume with the use of a respiratory-gated PET, resulting in a statistically significant decrease in PTV, after applying adapted margins in eight patients with 14 liver lesions scheduled for SBRT. By applying an individualised threshold to the gated-PET, an internal MTV was generated for each lesion. A gated PTV was created by adding $3 \mathrm{~mm}$ to account for set-up margins. This volume was compared to a PTV delineated with the help of a semi-automatic MTV obtained from the non-gated exam. A five $\mathrm{mm}$ radial and a $10 \mathrm{~mm}$ cranio-caudal margins were applied to account for tumour motion and set-up margins to create the PTV. A study of Altunbas et al. ${ }^{61}$ tried to obtain an optimal segmentation method for the delineation of 28 liver lesions scheduled for SBRT. However, large lesion-to-lesion variations were obtained. In a retrospective study of Van De Voorde et al. ${ }^{62}$, a 4D- $\left[{ }^{18} \mathrm{~F}\right]$ FDG-PET/CT was used for SBRT treatment planning in 33 patients with HCC or liver metastasis. Different fractionation schedules were used, depending on the location 
nearby OAR, with an equivalent dose in 2 Gy fractions (EQD2) between 62.5 Gy to $150 \mathrm{~Gy}$, delivered in three to 10 fractions. Delineation of the GTV was based on contrast-enhanced CT scan and FDG uptake on $\left[{ }^{18}\right.$ F]FDG-PET/CT, but no further details were given. The CTV, considered to be identical to the GTV, was modified to create an internal target volume, accounting for tumour motion using the 4D-[ $\left.{ }^{18} \mathrm{~F}\right] \mathrm{FDG}-\mathrm{PET} / \mathrm{CT}$. Before each treatment, a CBCT scan was made for accurate patient set-up. This study was performed to report treatment response outcomes at three months, local control rate and progression pattern, which were satisfying.

Based on the these limited studies, the value of PET in radiation treatment planning of liver lesions needs further research. 


\section{Rectal cancer}

Radiotherapy, either delivered as part of a long course chemoradiation regimen or as a short course radiotherapy, plays an important role in the multimodality treatment of rectal tumours ${ }^{63-65}$. During radiotherapy, volume and motion changes in bladder and rectal volume may lead to significant shape variation of the $\mathrm{CTV}^{66-68}$. Notwithstanding the potential benefit of daily plan adaptation for the treatment of patients with rectal cancer, to date, no data exist that focus on the use of $\left[{ }^{18} \mathrm{~F}\right] \mathrm{FDG}-\mathrm{PET}$ to improve coverage of the target volume during the course of treatment. A significant change in the mean $\left[{ }^{18} \mathrm{~F}\right]$ FDG-PET tumour volume during radiation treatment has been demonstrated before. Therefore the use of pretreatment imaging only as a basis for the entire treatment does not suffice and incorporation of biological imaging techniques in the radiotherapy planning could enable biology-driven adaptive radiation therapy ${ }^{69}$ (table 4).

In addition to the use of ART schedules to overcome daily variations in target volume, other researchers have focused on the delivery of an adaptive boost on the residual tumour volume in the second half of the treatment, with relatively small margins as a consequence of the reduced rectal volume in the second part of the treatment ${ }^{85-87}$. In contrast to this adaptive boost in the second part of the treatment, already in 2005 Ciernik et al. ${ }^{70}$ evaluated the accuracy of automated segmentation of the $\left.{ }^{18} \mathrm{~F}\right] \mathrm{FDG}$-PET signal for target volume definition. Based on this so-called biological target volume, the authors stated that this computed [ ${ }^{18}$ F]FDG-PET-based target volume definition could be useful for the definition of standardised simultaneous integrated boost volumes for IMRT. The role of such radiation dose intensification with SIB guided by $\left[{ }^{18} \mathrm{~F}\right] \mathrm{FDG}-\mathrm{PET} / \mathrm{CT}$ in preoperative chemoradiotherapy for locally advanced rectal cancer was assessed in forty patients in $2016^{71}$. However, no 
advantages in terms of primary tumour downstaging, downsizing or toxicity profile could be demonstrated in comparison to conventional schedules reported in historical series. Although no benefit was demonstrated in preoperative chemoradiotherapy, there might be a role for focal dose escalation guided by [ $\left.{ }^{18} \mathrm{~F}\right]$ FDG-PET for patients with a local recurrence of rectal cancer after surgery ${ }^{72}$. In a planning study of 12 patients receiving 40 Gy in 20 daily fractions of $2 \mathrm{~Gy}$, focal dose escalation with 6 Gy using IMRT with a dose-painting boost to tumour regions with a SUV value above 2.0 was considered to be safe. However, as this was a planning study, no clinical trial data were available.

The use of $\left[{ }^{18} \mathrm{~F}\right]$ FDG-PET has further been studied to optimise initial target volume definition in the preoperative radiation treatment for patients with rectal cancer. Indeed, the true anatomic-pathologic extension of the tumour may exceed the radiologic volume identified on $\mathrm{CT}^{70}$. Nevertheless, Anderson et al. ${ }^{73}$ showed that the mean $\left[{ }^{18} \mathrm{~F}\right] \mathrm{FDG}-\mathrm{PET}-$ based GTV was smaller than the CT-based GTV, resulting in a change in PTV in $17 \%$ of 23 patients. The real strength however of using [ $\left.{ }^{18} \mathrm{~F}\right]$ FDG-PET to optimise target volume definition lies in the co-registration of $\left[{ }^{18} \mathrm{~F}\right] \mathrm{FDG}-\mathrm{PET}$ with other imaging techniques such as $\mathrm{CT}$ or MRI, to delineate a more accurate biological target volume, as was demonstrated by several groups ${ }^{70,74-80}$. The use of co-registered $\left[{ }^{18} \mathrm{~F}\right] \mathrm{FDG}-\mathrm{PET} / \mathrm{CT}$ indeed showed a higher uniformity between observers' definition of the GTV in a study of 6 patients ${ }^{74}$. Furthermore, Ciernik et al. ${ }^{75}$ and Yavuz et al. ${ }^{76}$ both described a GTV increase when using a co-registered $\left[{ }^{18}\right.$ F]FDG-PET/CT, the former in 3 out of 6 patients leading to a PTV increase of $20 \%$, the latter showing an increase of the median GTV with 65\% without describing the effect on the PTV. In contrast to these findings, in a study of 36 patients, Paskeviciute et al. ${ }^{77}$ found that $\left[{ }^{18}\right.$ F]FDG-PET/CT GTVs were significantly smaller than CT-based GTVs, however these GTVs were contoured based on [18F]FDG-PET information only. We can therefore accept that in 
general an increase in the GTV is observed when using a $\left[{ }^{18} \mathrm{~F}\right] \mathrm{FDG}-\mathrm{PET} / \mathrm{CT}$-guided strategy. This increase in GTV could be clinically relevant when wanting to reduce the risk of a geographic miss when an additional radiation boost to the primary tumour is planned. Furthermore, both Bassi et al. ${ }^{78}$ and Kilic et al. ${ }^{79}$ demonstrated that also the CTV increased significantly when delineating a biological target volume under the guidance of $\left[{ }^{18} \mathrm{~F}\right] \mathrm{FDG}$-PET co-registration, which could again potentially minimise the risk of a geographic miss. Although CTV increased significantly, 3D-CRT or IMRT plans created with the guidance of $\mathrm{PET} / \mathrm{CT}$ however did not prove to be superior to the 3D-CRT and IMRT plans created with the guidance of $\mathrm{CT}^{79}$. A remark on target delineation using $\left[{ }^{18} \mathrm{~F}\right] \mathrm{FDG}-\mathrm{PET} / \mathrm{CT}$ has to be made however in terms of interobserver agreement for target delineation. Both Krengli et al. ${ }^{81}$ and Buijsen et al. ${ }^{82}$ found that $\left[{ }^{18} \mathrm{~F}\right]$ FDG-PET/CT may reduce the interobserver variability in GTV delineation, although less influence on the variability in CTV delineation was observed. To further optimise the $\left[{ }^{18} \mathrm{~F}\right] \mathrm{FDG}-\mathrm{PET} / \mathrm{CT}$-based target volume delineation, various automatic segmentation methods have been compared to define the biological tumour volume ${ }^{83}$. Large variations were shown in tumour volume delineation according to the segmentation algorithms, software products and manipulation of the $\left[{ }^{18} \mathrm{~F}\right] \mathrm{FDG}-\mathrm{PET} / \mathrm{CT}$ images and target volumes so that further investigation is needed before implementing such automatic segmentation methods in the clinical routine of radiotherapy planning. Also, the use of $\left[{ }^{18} \mathrm{~F}\right]$ FDG-PET/CT for target volume definition has been compared with MRI. Buijsen et al. ${ }^{82}$ found the GTV volume to decrease significantly from $46.8 \mathrm{cc}$ to $28.8 \mathrm{cc}$ when using $\left[{ }^{18} \mathrm{~F}\right.$ ]FDGPET/CT in addition to MRI. Another study further compared the use of $\left[{ }^{18} \mathrm{~F}\right] \mathrm{FDG}-\mathrm{PET} / \mathrm{CT}$ with MRI for target definition in rectal cancer using two different $\left[{ }^{18} \mathrm{~F}\right] \mathrm{FDG}-\mathrm{PET} / \mathrm{CT}$ segmentation algorithms and concluded that integration of MRI and $\left[{ }^{18} \mathrm{~F}\right] \mathrm{FDG}-\mathrm{PET} / \mathrm{CT}$ information into radiotherapy planning seemed feasible, although the superiority to a CT-based definition of 
the target volume for dose escalation remains to be proven ${ }^{80}$. Finally, Roels et al. ${ }^{84}$ explored the potential of two other PET-tracers for radiotherapy target definition: $\left[{ }^{18} \mathrm{~F}\right]-$ fluorothymidine $\left(\left[{ }^{18} \mathrm{~F}\right] \mathrm{FLT}\right)$ and $\left[{ }^{18} \mathrm{~F}\right]$-fluoromisonidazole $\left(\left[{ }^{18} \mathrm{~F}\right] \mathrm{FMISO}\right)$. While $\left[{ }^{18} \mathrm{~F}\right] \mathrm{FLT}$ and $\left[{ }^{18} \mathrm{~F}\right] \mathrm{FDG}$ showed good spatial correspondence and seemed most appropriate to integrate in target volume definition, $\left[{ }^{18} \mathrm{~F}\right] \mathrm{FMISO}$ was shown to be less useful due to the non-specific uptake in normotoxic tissue and tracer diffusion through the bowel wall. Nevertheless, no further research on $\left[{ }^{18} \mathrm{~F}\right] \mathrm{FLT}$ or $\left[{ }^{18} \mathrm{~F}\right] \mathrm{FMISO}$ for this purpose has been conducted.

In conclusion, the use of $\left[{ }^{18} \mathrm{~F}\right]$ FDG-PET seems useful for optimisation of the radiotherapy planning. However, whether an improved treatment planning using coregistered $\left[{ }^{18} \mathrm{~F}\right] \mathrm{FDG}-\mathrm{PET} / \mathrm{CT}$ translates in a clinical benefit remains an open question. 


\section{Anal cancer}

The current standard treatment for squamous cell carcinoma of the anal canal is chemoradiotherapy with concurrent 5 -fluorouracil and mitomycin ${ }^{88}$. The role of $\left[{ }^{18} \mathrm{~F}\right] \mathrm{FDG}$ PET has been well investigated for initial staging of patients with anal cancer and for the assessment of treatment response and follow-up ${ }^{89}$. Nevertheless, its potential as a tool for plan adaptation during the course of chemoradiotherapy has not yet been explored. Although no data are present for truly adaptive radiotherapy using $\left[{ }^{18} \mathrm{~F}\right] \mathrm{FDG}-\mathrm{PET}$, the use of ${ }^{18}$ F]FDG-PET has been investigated for the optimisation of target volume delineation ${ }^{73,90,91}$ and the adaptation of the initial radiotherapy plan for lymph node involvement ${ }^{92-97}$ or sparing of the bone marrow ${ }^{98-100}$ (table 5).

Variations in treatment volumes are relevant when using highly conformal techniques such as intensity modulated radiation therapy. As was discussed before for rectal tumours, Anderson et al. ${ }^{73}$ described a smaller mean GTV when using an $\left[{ }^{18} \mathrm{~F}\right] \mathrm{FDG}-\mathrm{PET}$-based delineation method compared to a CT-based method $\left(91.7\right.$ vs. $\left.99.6 \mathrm{~cm}^{3}\right)$. This however has to be interpreted carefully as only 3 of 23 investigated patients in this study had a tumour of the anal canal, in which in only one of the 3 patients the integration of the $\left.{ }^{[18} \mathrm{F}\right] \mathrm{FDG}$-PET volume with the planning volume resulted in a change in the PTV. In a group of 27 patients, Krengli et al. ${ }^{90}$ confirmed this reduction in the tumour GTV in $56 \%$ of patients when using an ${ }^{18}$ F]FDG-PET-based delineation method compared to a CT-based delineation method (51.5 vs $86.5 \mathrm{~cm}^{3}$ respectively), although fusion of both imaging techniques resulted in a significantly larger GTV $\left(95.7 \mathrm{~cm}^{3}\right)$, thereby reducing the risk of a geographic miss at the periphery of the tumour. Similarly, the $\left.{ }^{18} \mathrm{~F}\right] \mathrm{FDG}-\mathrm{PET} / \mathrm{CT}$ CTV was greater in $37 \%$ of patients than the CT-based CTV (1042.1 vs. $\left.991.8 \mathrm{~cm}^{3}\right)$. More recently, target volume delineation 
using an $\left[{ }^{18} \mathrm{~F}\right]$ FDG-PET/CT-based method was found to perform similar to a method combining $\mathrm{MRI}$ and $\mathrm{CT}$, though $\left[{ }^{18} \mathrm{~F}\right] \mathrm{FDG}-\mathrm{PET} / \mathrm{CT}$ appeared to have lower inter observer variability ${ }^{91}$. Unfortunately, target volumes were not compared with a CT-based method. Moreover, when looking only to the primary tumour GTV excluding the involved lymph nodes, less agreement was found for both delineation methods, which may be of importance for focal tumour boosting strategies.

Even disregarding the aforementioned role of $\left[{ }^{18} \mathrm{~F}\right]$ FDG-PET for target volume delineation, ample evidence exists that there is an important role in the detection of nodal involvement which may modify the initial radiation treatment plan ${ }^{92-97}$. In 2008, Nguyen et al. ${ }^{92}$ were the first to report on a modification in the radiotherapy plan in $19 \%$ of 48 retrospectively revised patients with anal cancer by increasing the dose to boost the ${ }^{18}$ F]FDG-PET upstaged lymph node regions. Similar results were reported in a prospective group of 61 patients, of whom in $13 \%$ an adaptation of the radiotherapy fields was needed based on nodal involvement as assessed on $\left[{ }^{18} \mathrm{~F}\right] \mathrm{FDG}-\mathrm{PET}^{93}$. In contrast to enlarging the radiotherapy fields or increasing the radiotherapy dose to $\left[{ }^{18} \mathrm{~F}\right] \mathrm{FDG}$-avid lymph nodes, another strategy to modify the initial treatment plan is to reduce the dose to CT-detected enlarged but non-[18 F]FDG-avid inguinal lymph nodes, as reported on by Mai et al. ${ }^{94}$. Dose reduction due to non- $\left[{ }^{18} \mathrm{~F}\right] \mathrm{FDG}$-avidity could be achieved in $15.4 \%$ of the 39 patients in this study, of which none developed local recurrence or distant metastases. Different groups combined both strategies of reducing or increasing either the radiation dose or the radiation treatment fields based on $\left[{ }^{18} \mathrm{~F}\right] \mathrm{FDG}$-PET staging for lymph node involvement. On a group of 22 patients with anal cancer, Bannas et al. ${ }^{95}$ showed that an initial CT-based radiotherapy plan was modified in $23 \%$ of cases. Mistrangelo et al. ${ }^{96}$ reported a modification of the radiotherapy fields in $12.6 \%$ of 53 patients. The most recent publication in which $\left[{ }^{18} \mathrm{~F}\right] \mathrm{FDG}$ - 
PET led to major changes in terms of radiotherapy fields and dose based on lymph node involvement, reported on radiotherapy treatment plan modifications in $17 \%$ of 23 patients ${ }^{97}$.

Finally, $\left[{ }^{18} \mathrm{~F}\right] \mathrm{FDG}-\mathrm{PET}$ can also be used to reduce the radiation dose to functional bone marrow when using an IMRT techniques for patients with anal cancer to reduce haematological toxicity associated with the standard chemoradiotherapy. In 12 patients with anal cancer, bone marrow subvolumes were segmented above the mean SUV and below the mean fat fraction within the pelvis and lumbar spine and their intersection was designated as functional bone marrow for IMRT planning ${ }^{98}$. For these patients, the functional bone marrow V10 (volume receiving $\geq 10 \mathrm{~Gy}$ ) and V20 (volume receiving $\geq 20 \mathrm{~Gy}$ ) were lower when applying functional bone marrow-sparing IMRT vs. total bone marrow-sparing IMRT. On the other hand, on a group of 10 patients, the incorporation of $\left[{ }^{18} \mathrm{~F}\right] \mathrm{FDG}$-PET into the automatic treatment planning process failed to decrease the dose to active bone marrow as compared to bone marrow definition using the outer bone contours ${ }^{99}$. Furthermore, a study in 45 patients did not show that the radiation dose delivered to $\left[{ }^{18} \mathrm{~F}\right]$ FDG-PET-defined regions of active bone marrow could better predict radiation-associated acute haematological toxicity than the radiation dose to the total bone marrow ${ }^{100}$.

In general, based on the available evidence, the main applicability of $\left[{ }^{18} \mathrm{~F}\right] \mathrm{FDG}-\mathrm{PET}$ for the adaptation of the radiation treatment of patients with anal cancer lies in the identification of involved lymph nodes and subsequent modification of a CT-based treatment plan. Clinical relevance of tumour target volume delineation and the identification of bonemarrow regions that can be avoided during radiotherapy however, need future investigation. 


\section{ACKNOWLEDGEMENTS}

Philippe Bulens is an aspirant investigator at the Research Foundation Flanders (FWO). Melissa Thomas is supported by Kom op tegen Kanker (Stand up to Cancer), the Flemish cancer society. Christophe M. Deroose and Karin Haustermans are senior clinical investigators at the Research Foundation Flanders (FWO).

The authors would like to thank the staff of the 2Bergen Biomedical Library of the KU Leuven for their help with the evidence acquisition for this review. 
CONFLICTS OF INTEREST

The authors declare no conflicts of interest. 


\section{$\underline{\text { REFERENCES }}$}

1. Macbeth F, Overgaard J. Expert reviews, systematic reviews and meta-analyses. Radiother Oncol 2002;64(3):233-4.

2. Patel AA, Wolfgang JA, Niemierko A, Hong TS, Yock T, Choi NC. Implications of Respiratory Motion as Measured by Four-Dimensional Computed Tomography for Radiation Treatment Planning of Esophageal Cancer. Int J Radiat Oncol Biol Phys $2009 ; 74(1): 290-6$.

3. Bouchard M, McAleer M, Starkschall G. Impact of gastric filling on radiation dose delivered to gastroesophageal junction tumors. Int J Radiat Oncol Biol Phys $2010 ; 77(1): 292-300$.

4. Hawkins MA, Brooks C, Hansen VN, Aitken A, Tait DM. Cone Beam Computed Tomography-Derived Adaptive Radiotherapy for Radical Treatment of Esophageal Cancer. Int J Radiat Oncol Biol Phys 2010;77(2):378-83.

5. Nyeng TB, Nordsmark M, Hoffmann L. Dosimetric evaluation of anatomical changes during treatment to identify criteria for adaptive radiotherapy in oesophageal cancer patients. Acta Oncol 2015;54(9):1467-73.

6. Minsky BBD, Pajak TF, Ginsberg RJ, Pisansky TM, Martenson J, Komaki R, et al. INT 0123 (Radiation Therapy Oncology Group 94-05) Phase III Trial of Combined-Modality Therapy for Esophageal Cancer: High-Dose Versus Standard-Dose Radiation Therapy. J Clin Oncol 2002;20(5):1167-74.

7. Nkhali L, Thureau S, Edet-Sanson A, Doyeux K, Benyoucef A, Gardin I, et al. FDG$\mathrm{PET} / \mathrm{CT}$ during concomitant chemo radiotherapy for esophageal cancer: Reducing target volumes to deliver higher radiotherapy doses. Acta Oncol 2015;54(6):909-15. 
8. Seol KH, Lee JE. PET/CT planning during chemoradiotherapy for esophageal cancer. Radiat Oncol J 2014;32(1):31-42.

9. Vrieze O, Haustermans K, De Wever W, Lerut T, Van Cutsem E, Ectors N, et al. Is there a role for FGD-PET in radiotherapy planning in esophageal carcinoma? Radiother Oncol 2004;73(3):269-75.

10. Konski A, Doss M, Milestone B, Haluszka O, Hanlon A, Freedman G, et al. The integration of 18-fluoro-deoxy-glucose positron emission tomography and endoscopic ultrasound in the treatment-planning process for esophageal carcinoma. Int J Radiat Oncol Biol Phys 2005;61(4):1123-8.

11. Foley KG, Morgan C, Roberts SA, Crosby T. Impact of Positron Emission Tomography and Endoscopic Ultrasound Length of Disease Difference on Treatment Planning in Patients with Oesophageal Cancer. Clin Oncol 2017;29(11):760-6.

12. Moureau-Zabotto L, Touboul E, Lerouge D, Deniaud-Alexandre E, Grahek D, Foulquier J-NN, et al. Impact of computed tomography (CT) and 18F-deoxyglucose positron emission tomography (FDG-PET) image fusion for conformal radiotherapy in esophageal carcinoma. Cancer Radiother 2005;9(2):152-60.

13. Leong T, Everitt C, Yuen K, Condron S, Hui A, Ngan SYK, et al. A prospective study to evaluate the impact of FDG-PET on CT-based radiotherapy treatment planning for oesophageal cancer. Radiother Oncol 2006;78(3):254-61.

14. Gondi V, Bradley K, Mehta M, Howard A, Khuntia D, Ritter M, et al. Impact of hybrid fluorodeoxyglucose positron-emission tomography/computed tomography on radiotherapy planning in esophageal and non-small-cell lung cancer. Int J Radiat Oncol Biol Phys 2007;67(1):187-95.

15. Muijs CT, Schreurs LM, Busz DM, Beukema JC, van der Borden AJ, Pruim J, et al. 
Consequences of additional use of PET information for target volume delineation and radiotherapy dose distribution for esophageal cancer. Radiother Oncol 2009;93(3):447-53.

16. le Grange F, Wickers S, Warry A, Warrilow J, Bomanji J, Tobias JS. Defining the target in cancer of the oesophagus: direct radiotherapy planning with fluorodeoxyglucose positron emission tomography-computed tomography. Clin Oncol 2015;27(3):160-7.

17. Thomas L, Lapa C, Bundschuh RA, Polat B, Sonke J-J, Guckenberger M. Tumour delineation in oesophageal cancer - A prospective study of delineation in PET and CT with and without endoscopically placed clip markers. Radiother Oncol 2015;116(2):269-75.

18. Niyazi M, Landrock S, Elsner A, Manapov F, Hacker M, Belka C, et al. Automated biological target volume delineation for radiotherapy treatment planning using FDGPET/CT. Radiat Oncol 2013;8(1):180.

19. Hong TS, Killoran JH, Mamede M, Mamon HJ. Impact of manual and automated interpretation of fused PET/CT data on esophageal target definitions in radiation planning. Int J Radiat Oncol Biol Phys 2008;72(5):1612-8.

20. Vali FS, Nagda S, Hall W, Sinacore J, Gao M, Lee SH, et al. Comparison of standardized uptake value-based positron emission tomography and computed tomography target volumes in esophageal cancer patients undergoing radiotherapy. Int J Radiat Oncol Biol Phys 2010;78(4):1057-63.

21. Encaoua J, Abgral R, Leleu C, El Kabbaj O, Caradec $P$, Bourhis D, et al. Intérêt de la tomographie par émission de positons au (18F)-fluorodésoxyglucose pour la planification de la radiothérapie des cancers de l'œsophage localement évolués ou inopérables. Cancer/Radiotherapie 2017;21(4):267-75. 
22. Yu W, Cai X-WW, Liu Q, Zhu Z-FF, Feng W, Zhang Q, et al. Safety of dose escalation by simultaneous integrated boosting radiation dose within the primary tumor guided by (18)FDG-PET/CT for esophageal cancer. Radiother Oncol 2015;114(2):195-200.

23. Ma J, Wang Z, Wang C, Chen E, Dong Y, Song Y, et al. Individualized Radiation Dose Escalation Based on the Decrease in Tumor FDG Uptake and Normal Tissue Constraints Improve Survival in Patients With Esophageal Carcinoma. Technol Cancer Res Treat 2017;16(1):75-80.

24. Vesprini D, Ung Y, Dinniwell R, Breen S, Cheung F, Grabarz D, et al. Improving observer variability in target delineation for gastro-oesophageal cancer--the role of (18F)fluoro2-deoxy-D-glucose positron emission tomography/computed tomography. Clin Oncol 2008;20(8):631-8.

25. Schreurs LMA, Busz DM, Paardekooper GMRM, Beukema JC, Jager PL, Van der Jagt EJ, et al. Impact of 18-fluorodeoxyglucose positron emission tomography on computed tomography defined target volumes in radiation treatment planning of esophageal cancer: reduction in geographic misses with equal inter-observer variability: PET/CT improves esophage. Dis esophagus 2010;23(6):493-501.

26. Mamede M, Fakhri G El, Abreu-E-Lima P, Gandler W, Nosé V, Gerbaudo VH. Preoperative estimation of esophageal tumor metabolic length in FDG-PET images with surgical pathology confirmation. Ann Nucl Med 2007;21(10):553-62.

27. Zhong X, Zhang B, Zhang W, Han A, Pingping Song J, Yang G, et al. Using 18FFluorodeoxyglucose Positron Emission Tomography to Estimate the Length of Gross Tumor in Patients with Squamous Cell Carcinoma of the Esophagus. Int J Radiat Oncol Biol Phys 2009;73(1):136-41.

28. Yu W, Fu XL, Zhang YJ, Xiang JQ, Shen L, Jiang GL, et al. GTV spatial conformity 
between different delineation methods by18FDG PET/CT and pathology in esophageal cancer. Radiother Oncol 2009;93(3):441-6.

29. Zhang G, Han D, Ma C, Lu J, Sun T, Liu T, et al. Gradient-based delineation of the primary GTV on FLT PET in squamous cell cancer of the thoracic esophagus and impact on radiotherapy planning. Radiat Oncol 2015;10:11.

30. Han D, Yu J, Yu Y, Zhang G, Zhong X, Lu J, et al. Comparison of18F-Fluorothymidine and18F-Fluorodeoxyglucose PET/CT in Delineating Gross Tumor Volume by Optimal Threshold in Patients With Squamous Cell Carcinoma of Thoracic Esophagus. Int J Radiat Oncol Biol Phys 2010;76(4):1235-41.

31. Wang $\mathrm{Y}-\mathrm{C}$, Hsieh T-C, Yu C-Y, Yen K-Y, Chen S-W, Yang S-N, et al. The clinical application of 4D 18F-FDG PET/CT on gross tumor volume delineation for radiotherapy planning in esophageal squamous cell cancer. J Radiat Res 2012;53(4):594-600.

32. Scarsbrook A, Ward G, Murray P, Goody R, Marshall K, McDermott G, et al. Respiratory-gated (4D) contrast-enhanced FDG PET-CT for radiotherapy planning of lower oesophageal carcinoma: feasibility and impact on planning target volume. BMC Cancer 2017;17(1):671.

33. Muijs CT, Beukema JC, Woutersen D, Mul VE, Berveling MJ, Pruim J, et al. Clinical validation of FDG-PET/CT in the radiation treatment planning for patients with oesophageal cancer. Radiother Oncol 2014;113(2):188-92.

34. Everitt C, Leong T. Influence of F-fluorodeoxyglucose-positron emission tomography on computed tomography-based radiation treatment planning for oesophageal cancer. Australas Radiol 2006;50(3):271-4.

35. Guo Y, Li J, Wang W, Zhang Y, Wang J, Duan Y, et al. Geometrical differences in target 
volumes based on18F-fluorodeoxyglucose positron emission tomography/computed tomography and four-dimensional computed tomography maximum intensity projection images of primary thoracic esophageal cancer. Dis Esophagus 2014;27(8):744-50.

36. Guo YL, Li J Bin, Shao Q, Li YK, Zhang P. Comparative evaluation of CT-based and PET/4DCT-based planning target volumes in the radiation of primary esophageal cancer. Int J Clin Exp Med 2015;8(11):21516-24.

37. Guo YL, Li J Bin, Zhang P, Zhang YJ. A comparative study of target volumes based on 18 F-FDG PET-CT and ten phases of 4DCT for primary thoracic squamous esophageal cancer. Onco Targets Ther 2017;10:177-84.

38. Wu C, Zhu Z. Diagnosis and evaluation of gastric cancer by positron emission tomography. World J Gastroenterol 2014;20(16):4574-85.

39. Dębiec K, Wydmański J, Gorczewska I, Leszczyńska P, Gorczewski K, Leszczyński W, et al. 18-Fluorodeoxy-Glucose Positron Emission Tomography- Computed Tomography (18-FDG-PET/CT) for Gross Tumor Volume (GTV) Delineation in Gastric Cancer Radiotherapy. Asian Pacific J cancer Prev 2017;18(11):2989-98.

40. Landry J, Catalano PJ, Staley C, Harris W, Hoffman J, Talamonti M, et al. Randomized phase II study of gemcitabine plus radiotherapy versus gemcitabine, 5-fluorouracil, and cisplatin followed by radiotherapy and 5-fluorouracil for patients with locally advanced, potentially resectable pancreatic adenocarcinoma. J Surg Oncol 2010;101(7):587-92.

41. Hammel P, Huguet F, van Laethem J-L, Goldstein D, Glimelius B, Artru P, et al. Effect of Chemoradiotherapy vs Chemotherapy on Survival in Patients With Locally Advanced Pancreatic Cancer Controlled After 4 Months of Gemcitabine With or Without 
Erlotinib: The LAP07 Randomized Clinical Trial. JAMA 2016;315(17):1844-53.

42. Liu F, Erickson B, Peng C, Li XA. Characterization and management of interfractional anatomic changes for pancreatic cancer radiotherapy. Int J Radiat Oncol Biol Phys 2012;83(3):e423-9.

43. Li Y, Hoisak JDP, Li N, Jiang C, Tian Z, Gautier Q, et al. Dosimetric benefit of adaptive re-planning in pancreatic cancer stereotactic body radiotherapy. Med Dosim $2015 ; 40(4): 318-24$.

44. Ates O, Ahunbay EE, Moreau M, Li XA. Technical Note: A fast online adaptive replanning method for VMAT using flattening filter free beams. Med Phys 2016;43(6):2756-64.

45. Dalah E, Moraru I, Paulson E, Erickson B, Li XA. Variability of target and normal structure delineation using multimodality imaging for radiation therapy of pancreatic cancer. Int J Radiat Oncol Biol Phys 2014;89(3):633-40.

46. Topkan E, Yavuz AA, Aydin M, Onal C, Yapar F, Yavuz MN. Comparison of CT and PETCT based planning of radiation therapy in locally advanced pancreatic carcinoma. J Exp Clin Cancer Res 2008;27(1):41.

47. Parlak C, Topkan E, Onal C, Reyhan M, Selek U. Prognostic value of gross tumor volume delineated by FDG-PET-CT-based radiotherapy treatment planning locally advanced pancreatic cancer treated with chemoradiotherapy. Ann Oncol 2012;23-37.

48. Li X-XX, Liu N-BB, Zhu L, Yuan X-KK, Yang C-WW, Ren P, et al. Consequences of additional use of contrast-enhanced 18F-FDG PET/CT in target volume delineation and dose distribution for pancreatic cancer. Br J Radiol 2015;88(1051):20140590.

49. Kishi T, Matsuo Y, Nakamura A, Nakamoto Y, Itasaka S, Mizowaki T, et al. Comparative evaluation of respiratory-gated and ungated FDG-PET for target volume definition in 
radiotherapy treatment planning for pancreatic cancer. Radiother Oncol $2016 ; 120(2): 217-21$.

50. Pretz JL, Blake MA, Killoran JH, Mamon HJ, Wo JY, Zhu AX, et al. Pilot study on the impact of F18-labeled thymidine PET/CT on gross tumor volume identification and definition for pancreatic cancer. Pract Radiat Oncol 2017;8(3):179-84.

51. Klaassen R, Bennink RJ, van Tienhoven G, Bijlsma MF, Besselink MGH, van Berge Henegouwen MI, et al. Feasibility and repeatability of PET with the hypoxia tracer [(18)F]HX4 in oesophageal and pancreatic cancer. Radiother Oncol 2015;116(1):94-9.

52. Wilson JM, Mukherjee S, Chu K-Y, Brunner TB, Partridge M, Hawkins M. Challenges in using (1)(8)F-fluorodeoxyglucose-PET-CT to define a biological radiotherapy boost volume in locally advanced pancreatic cancer. Radiat Oncol 2014;9(1):146.

53. Huang X, Knoble JL, Zeng M, Aguila FN, Patel T, Chambers LW, et al. Neoadjuvant Gemcitabine Chemotherapy followed by Concurrent IMRT Simultaneous Boost Achieves High RO Resection in Borderline Resectable Pancreatic Cancer Patients. PLoS One 2016;11(12):e0166606.

54. Phelip J-M, Vendrely V, Rostain F, Subtil F, Jouve J-L, Gasmi M, et al. Gemcitabine plus cisplatin versus chemoradiotherapy in locally advanced biliary tract cancer: Federation Francophone de Cancerologie Digestive 9902 phase II randomised study. Eur J Cancer 2014;50(17):2975-82.

55. Onal C, Topuk S, Yapar AF, Yavuz M, Topkan E, Yavuz A. Comparison of computed tomography-and positron emission tomography-based radiotherapy planning in cholangiocarcinoma. Onkologie 2013;36(9):484-90.

56. Habermehl D, Lindel K, Rieken S, Haase K, Goeppert B, Büchler MW, et al. Chemoradiation in patients with unresectable extrahepatic and hilar 
cholangiocarcinoma or at high risk for disease recurrence after resection: Analysis of treatment efficacy and failure in patients receiving postoperative or primary chemoradiation. Strahlentherapie und Onkol 2012;188(9):795-801.

57. Parlak C, Topkan E, Sonmez S, Onal C, Reyhan M. CT-versus coregistered FDG-PET/CTbased radiation therapy plans for conformal radiotherapy in colorectal liver metastases: A dosimetric comparison. Jpn J Radiol 2012;30(8):628-34.

58. Steffen IG, Wust P, Rühl R, Grieser C, Schnapauff D, Lüdemann L, et al. Value of Combined PET/CT for Radiation Planning in CT-Guided Percutaneous Interstitial HighDose-Rate Single-Fraction Brachytherapy for Colorectal Liver Metastases. Int J Radiat Oncol Biol Phys 2010;77(4):1178-85.

59. Bundschuh RA, Andratschke N, Dinges J, Duma MN, Astner ST, Brügel M, et al. Respiratory gated [18F]FDG PET/CT for target volume delineation in stereotactic radiation treatment of liver metastases. Strahlentherapie und Onkol 2012;188(7):5928.

60. Riou O, Serrano B, Azria D, Paulmier B, Villeneuve R, Fenoglietto P, et al. Integrating respiratory-gated PET-based target volume delineation in liver SBRT planning, a pilot study. Radiat Oncol 2014;9(1):1-9.

61. Altunbas C, Howells C, Proper M, Reddy K, Gan G, DeWitt P, et al. Evaluation of threshold and gradient based 18F-fluoro-deoxy-2-glucose hybrid positron emission tomographic image segmentation methods for liver tumor delineation. Pract Radiat Oncol 2014;4(4):217-25.

62. Van De Voorde L, Vanneste B, Houben R, Damen P, Van Den Bogaard J, Lammering G, et al. Image-guided stereotactic ablative radiotherapy for the liver: A safe and effective treatment. Eur J Surg Oncol 2015;41(2):249-56. 
63. Trial SRC. Improved Survival with Preoperative Radiotherapy in Resectable Rectal Cancer. N Engl J Med 1997;336:980-7.

64. Kapiteijn E, Marijnen CA, Nagtegaal ID, Putter H, Steup WH, Wiggers T, et al. Preoperative Radiotherapy combined with Total Mesorectal Excision for Resectable Rectal Cancer. N Engl J Med 2001;345(9):638-46.

65. Sauer R, Becker H, Hohenberger W, Rödel C, Wittekind C, Fietkau R, et al. Preoperative versus postoperative chemoradiotherapy for rectal cancer. N Engl J Med 2004;351(17):1731-40.

66. Nuyttens JJ, Robertson JM, Yan D, Martinez A. The variability of the clinical target volume for rectal cancer due to internal organ motion during adjuvant treatment. Int J Radiat Oncol Biol Phys 2002;53(2):497-503.

67. Tournel K, De Ridder M, Engels B, Bijdekerke P, Fierens Y, Duchateau M, et al. Assessment of intrafractional movement and internal motion in radiotherapy of rectal cancer using megavoltage computed tomography. Int J Radiat Oncol Biol Phys 2008;71(3):934-9.

68. Brierley JD, Dawson LA, Sampson E, Bayley A, Scott S, Moseley JL, et al. Rectal motion in patients receiving preoperative radiotherapy for carcinoma of the rectum. Int J Radiat Oncol Biol Phys 2011;80(1):97-102.

69. Haustermans K, Roels S, Verstraete J, Depuydt T, Slagmolen P. Adaptive RT in rectal cancer: Superior to 3D-CRT? A simple question, a complex answer. Strahlentherapie und Onkol 2007;183(SUPPL. 2):21-3.

70. Ciernik IF, Huser M, Burger C, Davis JB, Szekely G. Automated functional image-guided radiation treatment planning for rectal cancer. Int J Radiat Oncol Biol Phys 2005;62(3):893-900. 
71. Alongi F, Fersino S, Mazzola R, Fiorentino A, Giaj-Levra N, Ricchetti F, et al. Radiation dose intensification in pre-operative chemo-radiotherapy for locally advanced rectal cancer. Clin Transl Oncol 2016;19(2):1-8.

72. Jingu K, Ariga H, Kaneta T, Takai Y, Takeda K, Katja L, et al. Focal dose escalation using FDG-PET-guided intensity-modulated radiation therapy boost for postoperative local recurrent rectal cancer: A planning study with comparison of DVH and NTCP. BMC Cancer 2010;10:127.

73. Anderson C, Koshy M, Staley C, Esiashvili N, Ghavidel S, Fowler Z, et al. PET-CT Fusion in Radiation Management of Patients with Anorectal Tumors. Int J Radiat Oncol Biol Phys 2007;69(1):155-62.

74. Patel DA, Chang ST, Goodman KA, Quon A, Thorndyke B, Gambhir SS, et al. Impact of integrated PET/CT on variability of target volume delineation in rectal cancer. Technol Cancer Res Treat 2007;6(1):31-6.

75. Ciernik IF, Dizendorf E, Baumert BG, Reiner B, Burger C, Davis JB, et al. Radiation treatment planning with an integrated positron emission and computer tomography (PET/CT): A feasibility study. Int J Radiat Oncol Biol Phys 2003;57(3):853-63.

76. Yavuz MN, Topkan E, Yabuz AA, Aydin M, Onal C, Reyhan M, et al. FDG-PET/CT Imaging-Based Target Volume Delineation for Preoperative Conformal Radiotherapy of Rectal Carcinoma. Int J Hematol Oncol 2010;20(2):45-54.

77. Paskeviciute B, Bolling T, Brinkmann M, Rudykina G, Ernst I, Stegger L, et al. Impact of 18F-FDG-PET/CT on Staging and Irradiation of Patients with Locally Advanced Rectal Cancer. Strahlentherapie und Onkol 2009;185(4):260-5.

78. Bassi MC, Turri L, Sacchetti G, Loi G, Cannillo B, La Mattina P, et al. FDG-PET/CT Imaging for Staging and Target Volume Delineation in Preoperative Conformal 
Radiotherapy of Rectal Cancer. Int J Radiat Oncol Biol Phys 2008;70(5):1423-6.

79. Kiliç D, Catli S, Ulger S, Kapucu LÖLO, Kiliç D, Çatli S, et al. Is there any impact of $\mathrm{PET} / \mathrm{CT}$ on radiotherapy planning in rectal cancer patients undergoing preoperative IMRT? Turkish J Med Sci 2015;45(1):129-35.

80. Roels S, Slagmolen P, Nuyts J, Lee JA, Loeckx D, Maes F, et al. Biological Image-Guided Radiotherapy in Rectal Cancer: Challenges and Pitfalls. Int J Radiat Oncol Biol Phys 2009;75(3):782-90.

81. Krengli M, Cannillo B, Turri L, Bagnasacco P, Berretta L, Ferrara T, et al. Target volume delineation for preoperative radiotherapy of rectal cancer: inter-observer variability and potential impact of FDG-PET/CT imaging. Technol Cancer Res Treat 2010;9(4):393-8.

82. Buijsen J, van den Bogaard J, van der Weide H, Engelsman S, van Stiphout R, Janssen $M$, et al. FDG-PET-CT reduces the interobserver variability in rectal tumor delineation. Radiother Oncol 2012;102(3):371-6.

83. Withofs N, Bernard C, Van der Rest C, Martinive P, Hatt M, Jodogne S, et al. FDG PET / CT for rectal carcinoma radiotherapy treatment planning : comparison of functional volume delineation algorithms and clinical challenges. J Appl Clin Med Phys 2014;15(5):216-28.

84. Roels S, Slagmolen P, Nuyts J, Lee JA, Loeckx D, Maes F, et al. Biological image-guided radiotherapy in rectal cancer: is there a role for FMISO or FLT, next to FDG? Acta Oncol 2008;47(7):1237-48.

85. Passoni P, Fiorino C, Slim N, Ronzoni M, Ricci V, Di Palo S, et al. Feasibility of an adaptive strategy in preoperative radiochemotherapy for rectal cancer with imageguided tomotherapy: Boosting the dose to the shrinking tumor. Int J Radiat Oncol Biol 
Phys 2013;87(1):67-72.

86. Raso R, Scalco E, Fiorino C, Broggi S, Cattaneo GM, Garelli S, et al. Assessment and clinical validation of margins for adaptive simultaneous integrated boost in neoadjuvant radiochemotherapy for rectal cancer. Phys Medica.2015;31(2):167-72.

87. Maggiulli E, Fiorino C, Passoni P, Broggi S, Gianolini S, Salvetti C, et al. Characterisation of rectal motion during neo-adjuvant radiochemotherapy for rectal cancer with image-guided tomotherapy: Implications for adaptive dose escalation strategies. Acta Oncol 2012;51(3):318-24.

88. Northover J, James R, Meadows H, Wan S, Jitlal M, Ledermann J. Chemoradiation for the treatment of epidermoid anal cancer : 13-year follow-up of the first randomised UKCCCR Anal Cancer Trial (ACT I). Br J Cancer 2010;102(7):1123-8.

89. Mahmud A, Poon R, Jonker D. PET imaging in anal canal cancer: a systematic review and meta-analysis. Br J Radiol 2017;90(1080):20170370.

90. Krengli M, Milia ME, Turri L, Mones E, Bassi MC, Cannillo B, et al. FDG-PET/CT imaging for staging and target volume delineation in conformal radiotherapy of anal carcinoma. Radiat Oncol 2010;5:10.

91. Rusten E, Rekstad BL, Undseth C, Al-Haidari G, Hanekamp B, Hernes E, et al. Target volume delineation of anal cancer based on magnetic resonance imaging or positron emission tomography. Radiat Oncol 2017;12(1):147.

92. Nguyen BT, Joon DL, Khoo V, Quong G, Chao M, Wada M, et al. Assessing the impact of FDG-PET in the management of anal cancer. Radiother Oncol 2008;87(3):376-82.

93. de Winton E, Heriot AG, Ng M, Hicks RJ, Hogg A, Milner A, et al. The impact of 18fluorodeoxyglucose positron emission tomography on the staging, management and outcome of anal cancer. Br J Cancer 2009;100(5):693-700. 
94. Mai SK, Welzel G, Hermann B, Wenz F, Haberkorn U, Dinter DJJ. Can the radiation dose to CT-enlarged but FDG-PET-negative inguinal lymph nodes in anal cancer be reduced? Strahlentherapie und Onkol 2009;185(4):254-9.

95. Bannas P, Weber C, Adam G, Frenzel T, Derlin T, Mester J, et al. Contrast-enhanced [18F]fluorodeoxyglucose-positron emission tomography/computed tomography for staging and radiotherapy planning in patients with anal cancer. Int J Radiat Oncol Biol Phys 2011;81(2):445-51.

96. Mistrangelo M, Pelosi E, Bello M, Ricardi U, Milanesi E, Cassoni P, et al. Role of positron emission tomography-computed tomography in the management of anal cancer. Int J Radiat Oncol Biol Phys 2012;84(1):66-72.

97. Zimmermann M, Beer J, Bodis S, von Moos R, Vlachopoulou V, Zwahlen DR, et al. PETCT guided SIB-IMRT combined with concurrent 5-FU/MMC for the treatment of anal cancer. Acta Oncol 2017;56(12):1734-40.

98. Liang Y, Bydder M, Yashar CM, Rose BS, Cornell M, Hoh CK, et al. Prospective study of functional bone marrow-sparing intensity modulated radiation therapy with concurrent chemotherapy for pelvic malignancies. Int J Radiat Oncol Biol Phys 2013;85(2):406-14.

99. Franco P, Fiandra C, Arcadipane F, Trino E, Giglioli FR, Ragona R, et al. Incorporating (18)FDG-PET-defined pelvic active bone marrow in the automatic treatment planning process of anal cancer patients undergoing chemo-radiation. BMC Cancer 2017;17(1):710.

100. Rose BS, Jee K-WW, Niemierko A, Murphy JE, Blaszkowsky LS, Allen JN, et al. Irradiation of FDG-PET-defined active bone marrow subregions and acute hematologic toxicity in anal cancer patients undergoing chemoradiation. Int J Radiat Oncol Biol 
Phys 2016;94(4):747-54. 


\section{FIGURES AND TABLES}

\section{Figure 1.}

- $\quad$ Figure Title: Literature search

- Legend: N/A

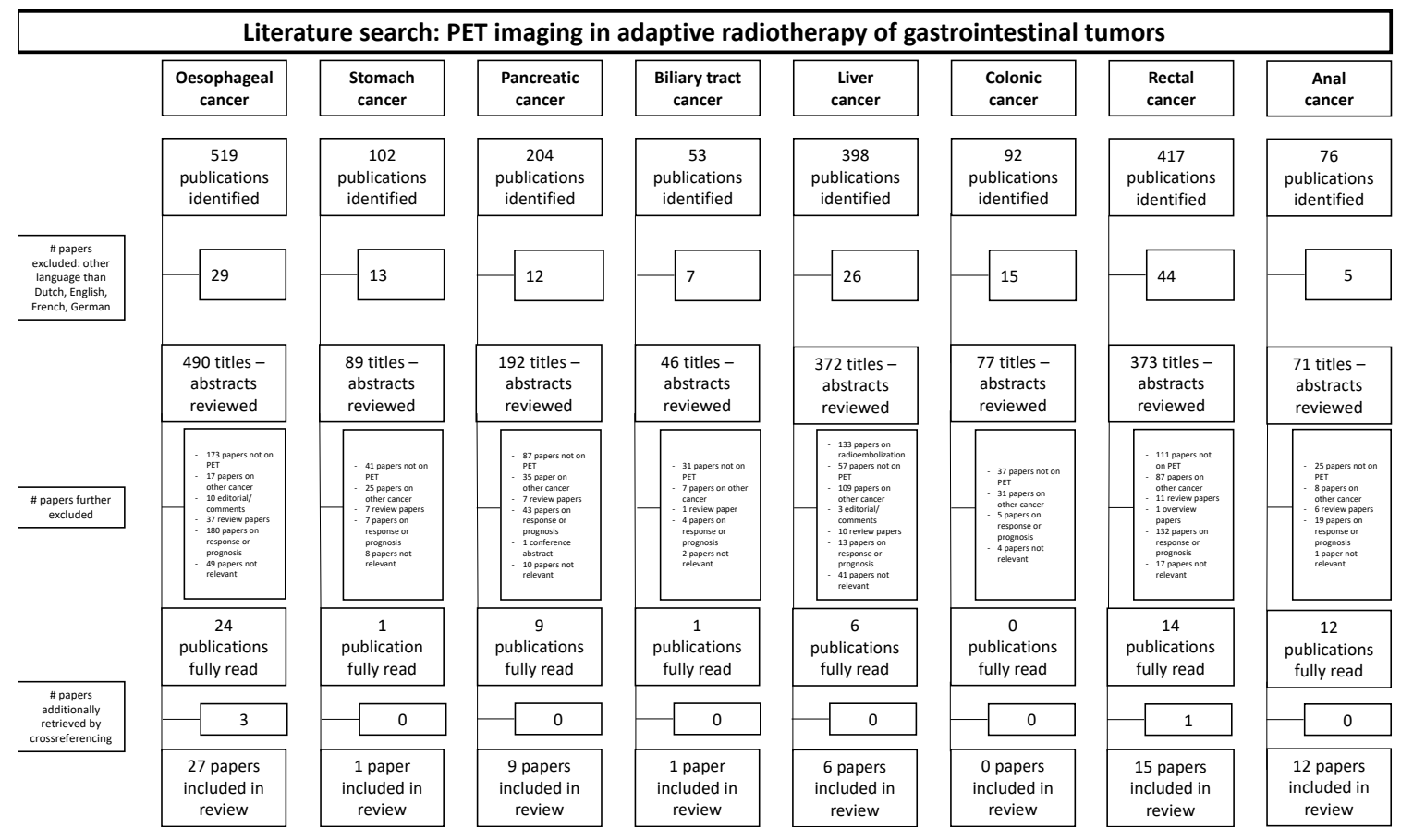


Table 1.

- Table Title: Overview and main research question of studies in radiation treatment planning of oesophageal cancer

- Table legend:

All studies used [18F]FDG-PET, except two were [18F]FLT was administered (mentioned in table).

$\mathrm{N}=$ number; $\mathrm{TV}=$ target volume; $\mathrm{OAR}=$ organs at risk; GTV = gross tumour volume; CTV = clinical target volume; PTV = planning target volume; SUV = standardized uptake value; $\mathrm{SBR}=$ signal-to-background ratio; $\mathrm{SD}=$ standard deviation; SUV $\mathrm{bgd}_{\text {b }}=$ SUV background normal oesophagus; $\mathrm{LN}=$ lymph nodes; [18F]FLT = [18F]-fluorothymidine; [18F]FDG $=[18 \mathrm{~F}]-$ fluorodeoxyglucose. 


\begin{tabular}{|c|c|c|c|c|c|c|c|c|c|c|c|c|}
\hline \multirow[t]{3}{*}{ Author } & \multirow[t]{3}{*}{ Year } & \multirow[t]{3}{*}{$\mathbf{N}$} & \multirow[t]{3}{*}{ Method of delineation } & \multicolumn{9}{|c|}{ Research question } \\
\hline & & & & \multicolumn{2}{|r|}{ TV modifications } & \multirow{2}{*}{ 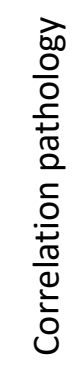 } & \multirow{2}{*}{ 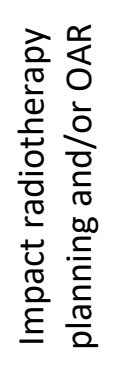 } & \multirow{2}{*}{ 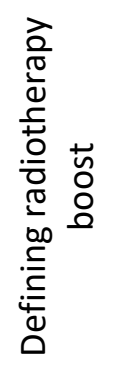 } & \multirow{2}{*}{ 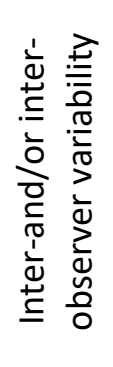 } & \multirow{2}{*}{ 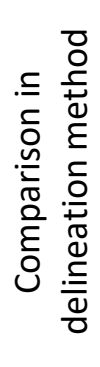 } & \multirow{2}{*}{ 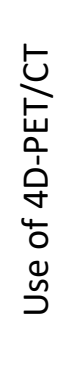 } & \multirow{2}{*}{ 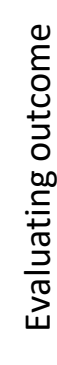 } \\
\hline & & & & 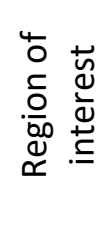 & $\frac{n}{\stackrel{\frac{n}{\pi}}{ \pm}}$ & & & & & & & \\
\hline Vrieze $^{9}$ & 2004 & 30 & Not described & CTV & involved LN & & & & & & & \\
\hline Konski $^{10}$ & 2005 & 25 & SUV $\geq 2.0,2.5,3.0$ & GTV & length tumour & & & & & & & \\
\hline Foley $^{11}$ & 2017 & 160 & Visual & GTV & length tumour + LN & & & & & & & \\
\hline $\begin{array}{l}\text { Moureau- } \\
\text { Zabotto }{ }^{12}\end{array}$ & 2005 & 34 & Visual & GTV & length/volume tumour + LN & & $x$ & & & & & \\
\hline Leong ${ }^{13}$ & 2006 & 16 & Visual (liver SBR) & GTV & volume/overlap tumour + LN & & $x$ & & & & & \\
\hline Gondi $^{14}$ & 2007 & 16 & Visual (liver SBR) & GTV & $\begin{array}{l}\text { volume/overlap tumour } \\
\text { (+LN?) }\end{array}$ & & & & & & & \\
\hline Muijs ${ }^{15}$ & 2009 & 21 & Visual (liver SBR) & GTV & $\begin{array}{l}\text { length/volume/overlap } \\
\text { tumour + LN }\end{array}$ & & $x$ & & & & & \\
\hline Le Grange $^{16}$ & 2015 & 19 & Visual & GTV & $\begin{array}{l}\text { length/volume/overlap } \\
\text { tumour + LN }\end{array}$ & & $\mathrm{X}$ & & & & & \\
\hline Thomas ${ }^{17}$ & 2015 & 20 & $\begin{array}{l}\text { Visual vs. SUV } \geq 2.0,2.5,3.0 \text { vs. SUV } \geq \\
20 \%, 35 \%, 40 \%, 45 \% \text { SUV }_{\max } \text { Vs. target-to- } \\
\text { background-method (background near } \\
\text { lesion) vs. gradient-based method }\end{array}$ & GTV & $\begin{array}{l}\text { length/volume/overlap } \\
\text { tumour }\end{array}$ & & & & & $\mathrm{x}$ & & \\
\hline Niyazi $^{18}$ & 2013 & 20 & $\begin{array}{l}\text { SUV } \geq 38 \%, 42 \%, 47 \%, 50 \% S U_{\max } \text { VS. } \\
\text { SUV } \geq \text { mean liver SUV + 3SD }\end{array}$ & GTV & $\begin{array}{l}\text { volume/overlap tumour } \\
\text { (+LN?) }\end{array}$ & & & & & $x$ & & \\
\hline Hong ${ }^{19}$ & 2008 & 25 & Visual vs. SUV $\geq$ mean liver SUV + 2SD & GTV & length/volume tumour + LN & & & & & $x$ & & \\
\hline Vali ${ }^{20}$ & 2010 & 22 & $\begin{array}{l}\text { SUV } \geq 2.0,2.5,3.0,3.5 \text { vs. SUV } \geq 40 \% \\
45 \%, 50 \% S_{\text {max }} \text { VS. SUV } \geq \text { mean liver } \\
\text { SUV + 1SD, 2SD, 3SD, } 4 S D\end{array}$ & GTV & $\begin{array}{l}\text { volume/overlap radial extent } \\
\text { tumour }\end{array}$ & & & & & $X$ & & \\
\hline Encaoua ${ }^{21}$ & 2017 & 58 & SUV $\geq 2.5$ vs. SUV $\geq 40 \%$ SUV $_{\max }$ Vs. & GTV & length/volume/overlap & & $x$ & $x$ & & $x$ & & \\
\hline
\end{tabular}




\begin{tabular}{|c|c|c|c|c|c|c|c|c|c|c|c|c|}
\hline & & & $\begin{array}{l}\text { target-to-background method (intra- } \\
\text { aortic activity) }\end{array}$ & & tumour + LN & & & & & & & \\
\hline$Y u^{22}$ & 2015 & 25 & SUV $\geq 50 \%$ SUV $_{\max }$ & - & & & $X$ & $x$ & & & & \\
\hline $\mathrm{Ma}^{23}$ & 2017 & 112 & - & - & & & & $x$ & & & & $\mathrm{x}$ \\
\hline Vesprini ${ }^{24}$ & 2008 & 10 & Visual & GTV & $\begin{array}{l}\text { length/volume/overlap } \\
\text { tumour }\end{array}$ & & & & $\mathrm{X}$ & & & \\
\hline Schreurs ${ }^{25}$ & 2010 & 28 & Visual (liver SBR) & $\begin{array}{l}\text { GTV, } \\
\text { CTV, } \\
\text { PTV }\end{array}$ & $\begin{array}{l}\text { length/volume/overlap } \\
\text { tumour + LN }\end{array}$ & & & & $\mathrm{X}$ & & & \\
\hline Mamede 26 & 2006 & 17 & $\begin{array}{l}\text { SUV } \geq \text { mean liver SUV + OSD, 1SD, 2SD, } \\
3 S D, 4 S D\end{array}$ & - & & $\mathrm{X}$ & & & & $\mathrm{X}$ & & \\
\hline Zhong 27 & 2009 & 36 & Visual vs. SUV $\geq 2.5$ vs. SUV $\geq 40 \%$ SUV $_{\max }$ & & & $\mathrm{X}$ & & & & $x$ & & \\
\hline$Y u^{28}$ & 2009 & 16 & $\begin{array}{l}\text { SUV }_{\text {bgd }}+20 \%\left(\text { SUV }_{\max }-S U V_{\text {bgd }}\right) \text { vs. } \\
\text { SUV }_{\text {bgd }}+40 \%\left(\text { SUV }_{\max }-S U V_{\text {bgd }}\right) \text { vs. SUV } \geq 2.5 \\
\text { vs. SUV } \geq 40 \% \text { SUV }_{\max }\end{array}$ & GTV & $\begin{array}{l}\text { length/volume/overlap } \\
\text { tumour }\end{array}$ & $x$ & & & & $\mathrm{x}$ & & \\
\hline Zhang 29 & 2015 & 10 & $\begin{array}{l}\text { Using [18F]FLT: Gradient-based method } \\
\text { vs. SUV } \geq 1.4 \text { vs. SUV } \geq 30 \% \text { SUV }_{\max }\end{array}$ & GTV & $\begin{array}{l}\text { length/volume/overlap } \\
\text { tumour }\end{array}$ & $x$ & $x$ & & & $x$ & & \\
\hline $\operatorname{Han}^{30}$ & 2010 & 22 & $\begin{array}{l}\text { Using [18F]FLT: Visual vs. SUV } \geq 1.3,1.4 \\
1.5 \text { vs. SUV } \geq 20 \%, 25 \%, 30 \% S_{\max } \\
\text { Using [18F]FDG: Visual vs. SUV } \geq 2.5 \text { vs. } \\
\text { SUV } \geq 40 \% \text { SUV }_{\max }\end{array}$ & - & & $x$ & $x$ & & & $x$ & & \\
\hline Wang ${ }^{31}$ & 2012 & 12 & $\begin{array}{l}\text { SUV } \geq 2.0,2.5 \text { vs. SUV } \geq 15 \%, 20 \%, 25 \% \\
30 \%, 40 \%, 50 \% \text { SUV }_{\max }\end{array}$ & GTV & $\begin{array}{l}\text { length/volume/overlap } \\
\text { tumour }\end{array}$ & & & & & $x$ & $x$ & \\
\hline Scarsbrook 32 & 2017 & 9 & Visual & $\begin{array}{l}\text { GTV, } \\
\text { ITV, } \\
\text { PTV }\end{array}$ & $\begin{array}{l}\text { length/volume/overlap } \\
\text { tumour + LN }\end{array}$ & & $x$ & & & & $x$ & \\
\hline Muijs ${ }^{33}$ & 2014 & 90 & Visual (liver SBR) & $\begin{array}{l}\text { GTV, } \\
\text { CTV }\end{array}$ & $\begin{array}{l}\text { length/volume/overlap } \\
\text { tumour + LN }\end{array}$ & & $x$ & & & & & $\mathrm{x}$ \\
\hline
\end{tabular}




\section{Table 2.}

- Table title: Overview and main research question of studies in radiation treatment planning of pancreatic cancer

- Table legend:

All studies used $\left[{ }^{18} \mathrm{~F}\right] \mathrm{FDG}-\mathrm{PET}$ except two where $\left[{ }^{18} \mathrm{~F}\right] \mathrm{FLT}$ or $\left[{ }^{18} \mathrm{~F}\right] \mathrm{HX} 4$ was administered (mentioned in table)

$\mathrm{N}=$ number; $\mathrm{TV}=$ target volume; OAR = organs at risk; GTV = gross tumour volume; CTV = clinical target volume; PTV = planning target volume; SUV = standardized uptake value; $\mathrm{SBR}=$ signal-to-background ratio; $\mathrm{TBR}=$ tumour-to-background ratio SD = standard deviation; $L N=$ lymph nodes; $\left[{ }^{18} \mathrm{~F}\right] \mathrm{FDG}=\left[{ }^{18} \mathrm{~F}\right]$-fluorodeoxyglucose; $\left[{ }^{18} \mathrm{~F}\right] \mathrm{FLT}=\left[{ }^{18} \mathrm{~F}\right]$-fluorothymidine; $\left[{ }^{18} \mathrm{~F}\right] \mathrm{HX} 4=\left[{ }^{18} \mathrm{~F}\right]-3-$ Fluoro-2-(4-((2-nitro-1H-imidazol-1-yl)methyl)-1H-1,2,3triazol-1-yl)propan-1-ol. 


\begin{tabular}{|c|c|c|c|c|c|c|c|c|c|c|c|c|}
\hline \multirow[t]{3}{*}{ Author } & \multirow[t]{3}{*}{ Year } & \multirow[t]{3}{*}{$\mathbf{N}$} & \multirow[t]{3}{*}{ Method of delineation } & \multicolumn{9}{|c|}{ Research question } \\
\hline & & & & \multicolumn{2}{|r|}{ TV modifications } & \multirow{2}{*}{ 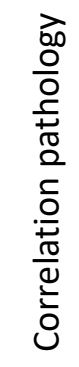 } & \multirow{2}{*}{ 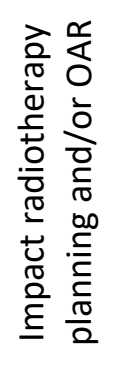 } & \multirow{2}{*}{ 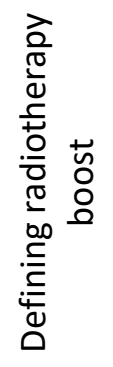 } & \multirow{2}{*}{ 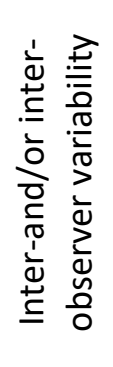 } & \multirow{2}{*}{ 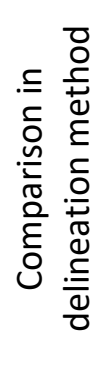 } & \multirow{2}{*}{ 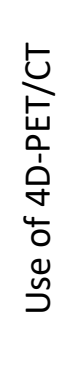 } & \multirow{2}{*}{ 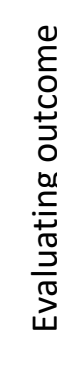 } \\
\hline & & & & 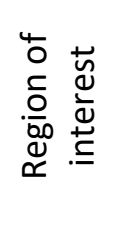 & $\begin{array}{l}\frac{n}{\pi} \\
\stackrel{ \pm}{0} \\
0\end{array}$ & & & & & & & \\
\hline Dalah ${ }^{45}$ & 2014 & 19 & $\begin{array}{l}\text { SUV } \geq 2.5 \text { vs. SUV } \geq 40 \% \text { SUV }_{\max } \text { Vs. SUV } \geq \\
50 \% \text { SUV }_{\max }\end{array}$ & GTV & volume tumour & & & & & $x$ & & \\
\hline Topkan ${ }^{46}$ & 2008 & 14 & Visual & GTV & volume tumour $+\mathrm{LN}$ & & $x$ & & & & & \\
\hline Parlak ${ }^{47}$ & 2012 & 30 & Visual & GTV & volume tumour + LN & & & & & & & $X$ \\
\hline $\mathbf{L i}^{48}$ & 2015 & 21 & SUV $\geq 2.5$ or $S U V \geq 40 \%$ SUV $_{\max }$ & GTV & volume tumour + LN & & $x$ & & & $\mathrm{X}$ & & \\
\hline Kishi $^{49}$ & 2016 & 14 & SUV $\geq 50 \%$ SUV $_{\max }$ & ITV & volume + motion tumour & & & & & & $X$ & \\
\hline Pretz 50 & 2017 & 9 & Using $\left[{ }^{18} \mathrm{~F}\right] \mathrm{FLT}$ : Visual & GTV & volume/overlap tumour + LN & & $x$ & & $x$ & & & \\
\hline Klaassen ${ }^{51}$ & 2015 & 13 & Using $\left[{ }^{18} \mathrm{~F}\right] \mathrm{H} X 4: \mathrm{TBR} \geq 1.0$ & - & hypoxic volume tumour & & $x$ & & & & & \\
\hline Wilson $^{52}$ & 2014 & 17 & SUV $\geq 40 \%$ SUV $_{\max }$ Vs. SUV $\geq 50 \%$ SUV $_{\max }$ & GTV & volume/overlap tumour & & & $\mathrm{X}$ & & & & $\mathrm{X}$ \\
\hline Huang 53 & 2016 & 25 & Not described & GTV & & & & $x$ & & & & $\mathrm{X}$ \\
\hline
\end{tabular}




\section{Table 3.}

- Table title: Overview and main research question of studies in radiation treatment planning of liver cancer

- Table legend:

All studies used [18F]FDG-PET.

$\mathrm{N}=$ number; $\mathrm{TV}=$ target volume; $\mathrm{OAR}=$ organs at risk; $\mathrm{GTV}=$ gross tumour volume; MTV = metabolic tumour volume; $\mathrm{CTV}=$ clinical target volume; $\mathrm{PTV}=$ planning target volume; SUV = standardized uptake value; $\mathrm{SBR}=$ signal-tobackground ratio; SD = standard deviation; $\mathrm{SUV}_{\mathrm{bgd}}=\mathrm{SUV}$ background normal liver; $\mathrm{EBRT}=$ external beam radiotherapy; $\mathrm{BT}=$ brachytherapy; $\mathrm{SBRT}=$ stereotactic body radiation therapy; $\mathrm{HCC}=$ hepatocellular carcinoma; $\mathrm{LN}=$ lymph nodes; [18F]FDG = [18F]-fluorodeoxyglucose. 


\begin{tabular}{|c|c|c|c|c|c|c|c|c|c|c|c|c|}
\hline \multirow[t]{3}{*}{ Author } & \multirow[t]{3}{*}{ Year } & \multirow[t]{3}{*}{$\mathbf{N}$} & \multirow[t]{3}{*}{ Method of delineation } & \multicolumn{9}{|c|}{ Research question } \\
\hline & & & & \multicolumn{2}{|r|}{ TV modifications } & \multirow{2}{*}{ 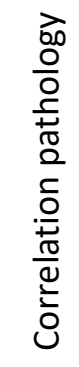 } & \multirow{2}{*}{ 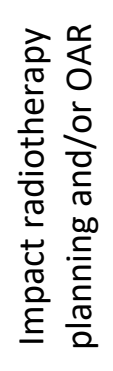 } & \multirow{2}{*}{ 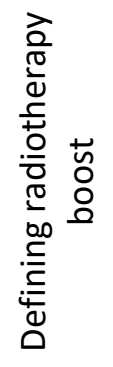 } & \multirow{2}{*}{ 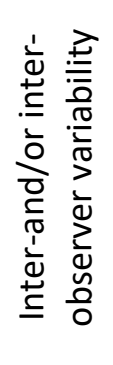 } & \multirow{2}{*}{ 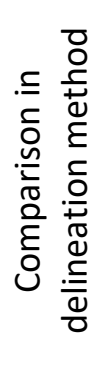 } & \multirow{2}{*}{ 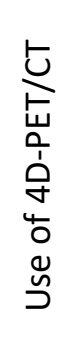 } & \multirow{2}{*}{ 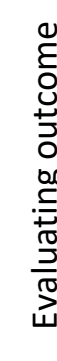 } \\
\hline & & & & 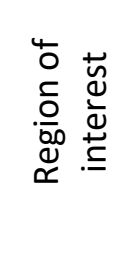 & $\frac{n}{\stackrel{0}{\pi}}$ & & & & & & & \\
\hline Parlak 57 & 2012 & 38 & SUV $\geq 10 \%$ liver SUV & GTV & $\begin{array}{l}\text { volume tumour } \\
\text { colorectal metastases - BT }\end{array}$ & & $x$ & & & & & \\
\hline Steffen ${ }^{58}$ & 2010 & 38 & Visual & CTV & $\begin{array}{l}\text { volume/overlap tumour } \\
\text { colorectal metastases - EBRT }\end{array}$ & & $\mathrm{x}$ & & & & & $x$ \\
\hline Bundschuh 59 & 2012 & 16 & $\begin{array}{l}\text { Visual (SBR) vs. adaptive threshold-based } \\
\text { method }\end{array}$ & GTV & $\begin{array}{l}\text { volume tumour } \\
\text { metastases - SBRT }\end{array}$ & & & & $x$ & $x$ & $x$ & \\
\hline Riou $^{60}$ & 2014 & 14 & $\begin{array}{l}\text { Background-based method ( }>S U V_{\max } \\
\text { normal liver) }\end{array}$ & $\begin{array}{c}\text { (inter- } \\
\text { nal) } \\
\text { MTV, } \\
\text { PTV }\end{array}$ & $\begin{array}{l}\text { volume tumour } \\
\text { metastases - SBRT }\end{array}$ & & & & & & $X$ & \\
\hline Altunbas ${ }^{61}$ & 2014 & 28 & $\begin{array}{l}\text { Visual vs. } S U V_{b g d}+3 S D\left(S U V_{b g d}\right) \text { vs. } \\
S V_{b g d}+10 / 20 / 30 / 40 / 50 \%\left(S U V_{\text {max }}-S U V_{b g d}\right) \\
\text { vs. gradient-based method }\end{array}$ & GTV & $\begin{array}{l}\text { overlap tumour } \\
\text { metastases - SBRT }\end{array}$ & & & & $x$ & $x$ & & \\
\hline $\begin{array}{l}\text { Van De } \\
\text { Voorde }\end{array}$ & 2015 & 39 & Not described & - & metastases or HCC - SBRT & & & & & & $x$ & $x$ \\
\hline
\end{tabular}




\section{Table 4.}

- Table title: Overview and main research question of studies in radiation treatment planning of rectal cancer

- Table legend:

All studies used $\left[{ }^{18} \mathrm{~F}\right] \mathrm{FDG}-\mathrm{PET}$, except one were $\left[{ }^{18} \mathrm{~F}\right] \mathrm{FLT}$ and $\left[{ }^{18} \mathrm{~F}\right] \mathrm{FMISO}$ was used (mentioned in table).

$\mathrm{N}=$ number; TV = target volume; OAR = organs at risk; GTV = gross tumour volume; CTV = clinical target volume; PTV = planning target volume; SUV = standardized uptake value; $\mathrm{SBR}=$ signal-to-background ratio; $\mathrm{SD}=$ standard deviation; $\mathrm{LN}=$ lymph nodes; $\left[{ }^{18} \mathrm{~F}\right] \mathrm{FLT}=\left[{ }^{18} \mathrm{~F}\right]$-fluorothymidine; $\left[{ }^{18} \mathrm{~F}\right] \mathrm{FDG}=\left[{ }^{18} \mathrm{~F}\right]$-fluorodeoxyglucose; $\quad\left[{ }^{18} \mathrm{~F}\right] \mathrm{FMISO}=\left[{ }^{18} \mathrm{~F}\right]-$ fluoromisonidazole. 


\begin{tabular}{|c|c|c|c|c|c|c|c|c|c|c|c|c|}
\hline \multirow[t]{3}{*}{ Author } & \multirow[t]{3}{*}{ Year } & \multirow[t]{3}{*}{$\mathbf{N}$} & \multirow[t]{3}{*}{ Method of delineation } & \multicolumn{9}{|c|}{ Research question } \\
\hline & & & & \multicolumn{2}{|r|}{ TV modifications } & \multirow{2}{*}{ 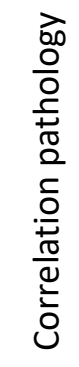 } & \multirow{2}{*}{ 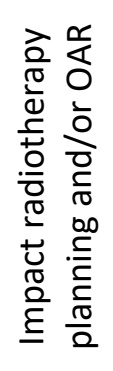 } & \multirow{2}{*}{ 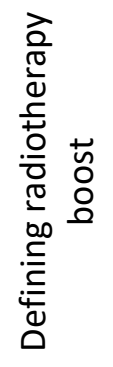 } & \multirow{2}{*}{ 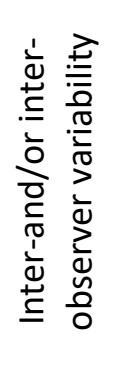 } & \multirow{2}{*}{ 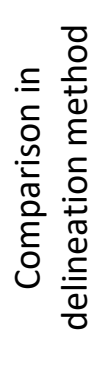 } & \multirow{2}{*}{ 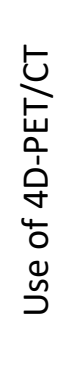 } & \multirow{2}{*}{ 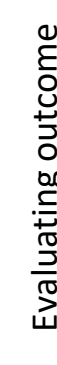 } \\
\hline & & & & 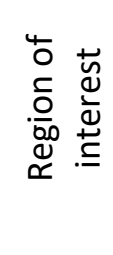 & $\begin{array}{l}\frac{n}{\bar{T}} \\
\stackrel{+}{\Delta} \\
0\end{array}$ & & & & & & & \\
\hline Ciernik $^{70}$ & 2005 & 11 & SUV $\geq 40 \%$ SUV $_{\max }$ & GTV & Volume tumour & & $x$ & $\mathrm{X}$ & & & & \\
\hline Alongi $^{71}$ & 2016 & 40 & SUV $\geq 5$ & $\begin{array}{l}\text { CTV- } \\
\text { SIB }\end{array}$ & volume tumour + LN & & & $x$ & & & & $x$ \\
\hline Jingu ${ }^{72}$ & 2010 & 12 & SUV $\geq 2$ & CTV & Volume tumour & & $x$ & $x$ & & & & \\
\hline Anderson ${ }^{73}$ & 2007 & 23 & Visual & $\begin{array}{l}\text { GTV } \\
\text { PTV }\end{array}$ & volume/overlap tumour & & $X$ & & & $x$ & & \\
\hline Patel ${ }^{74}$ & 2007 & 6 & Visual & GTV & volume tumour + LN & & $x$ & & $x$ & & & \\
\hline Ciernik $^{75}$ & 2003 & 6 & Visual & $\begin{array}{l}\text { GTV } \\
\text { PTV }\end{array}$ & volume tumour + LN & & & & & $x$ & & \\
\hline Yavuz ${ }^{76}$ & 2010 & 23 & Visual & GTV & volume tumour & & & & & $x$ & & \\
\hline Paskeviciute $^{77}$ & 2009 & 36 & SUV $\geq 2.5$ & GTV & volume/overlap tumour & & $x$ & & & $x$ & & \\
\hline Bassi $^{78}$ & 2008 & 25 & $\mathrm{SUV} \geq 40 \% \mathrm{SUV}_{\max }$ & $\begin{array}{l}\text { GTV } \\
\text { CTV }\end{array}$ & volume tumour + LN & & & & & $x$ & & \\
\hline Kiliç ${ }^{79}$ & 2015 & 20 & $\mathrm{SUV} \geq 40 \% \mathrm{SUV}_{\max }$ & $\begin{array}{l}\text { GTV } \\
\text { CTV }\end{array}$ & volume tumour & & $x$ & & & $x$ & & \\
\hline Roels $^{80}$ & 2009 & 15 & $\begin{array}{l}\text { Signal-to-background method vs. } \\
\text { gradient-based method }\end{array}$ & GTV & volume/overlap tumour & $\mathrm{X}$ & & & & $x$ & & \\
\hline Krengli ${ }^{81}$ & 2010 & 2 & $S U V \geq 40 \% S_{\text {SUax }}$ & $\begin{array}{l}\text { GTV } \\
\text { CTV }\end{array}$ & volume tumour + LN & & & & $x$ & & & \\
\hline Buijsen $^{82}$ & 2012 & 42 & Signal-to-background method & $\begin{array}{l}\text { GTV } \\
\text { CTV }\end{array}$ & volume tumour & & & & $X$ & $x$ & & \\
\hline Withofs ${ }^{83}$ & 2014 & 31 & $\begin{array}{l}\text { SUV } \geq 45 \% \text { SUV }_{\max }(E B W, \text { Philips) vs. SUV } \\
\geq 45 \% \text { SUV }_{\max }(\text { OASIS, Segami) vs. SUV } \geq\end{array}$ & GTV & volume tumour & & & & & $x$ & & \\
\hline
\end{tabular}




\begin{tabular}{|l|l|l|l|l|l|l|l|l|l|}
\hline & & & $\begin{array}{l}2.5 \text { (EBW, Philips) vs. SUV } \geq 2.5 \text { (OASIS, } \\
\text { Segami) vs. Fuzzy Locally Adpated } \\
\text { Bayesian algorithm vs. gradient-based } \\
\text { method }\end{array}$ & & & \\
\hline Roels 84 & 2008 & 15 & $\begin{array}{l}\text { Gradient-based method FDG vs. FLT vs. } \\
\text { FMISO }\end{array}$ & GTV & volume/overlap tumour & & \\
\hline
\end{tabular}


Table 5.

- $\quad$ Table title: Overview and main research question of studies in radiation treatment planning of anal cancer

- Table legend:

All studies used $\left[{ }^{18}\right.$ F]FDG-PET.

$\mathrm{N}=$ number; $\mathrm{TV}=$ target volume; $\mathrm{OAR}=$ organs at risk; GTV = gross tumour volume; CTV = clinical target volume; PTV = planning target volume; SUV = standardized uptake value; SBR = signal-to-background ratio; $\mathrm{SD}=$ standard deviation; $\mathrm{LN}=$ lymph nodes; $\left[{ }^{18} \mathrm{~F}\right] \mathrm{FDG}=\left[{ }^{18} \mathrm{~F}\right]-$ fluorodeoxyglucose. 


\begin{tabular}{|c|c|c|c|c|c|c|c|c|c|c|c|c|}
\hline \multirow[t]{3}{*}{ Author } & \multirow[t]{3}{*}{ Year } & \multirow[t]{3}{*}{$\mathbf{N}$} & \multirow[t]{3}{*}{ Method of delineation } & \multicolumn{9}{|c|}{ Research question } \\
\hline & & & & \multicolumn{2}{|r|}{ TV modifications } & \multirow{2}{*}{ 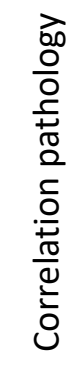 } & \multirow{2}{*}{ 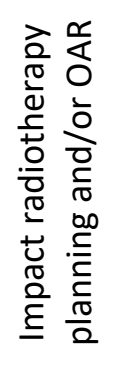 } & \multirow{2}{*}{ 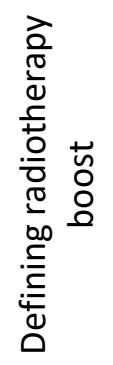 } & \multirow{2}{*}{ 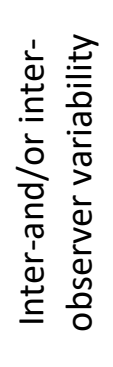 } & \multirow{2}{*}{ 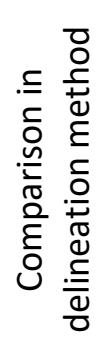 } & \multirow{2}{*}{ 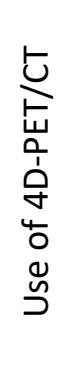 } & \multirow{2}{*}{ 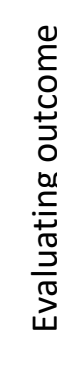 } \\
\hline & & & & 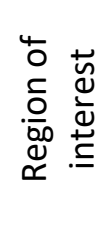 & $\frac{n}{\stackrel{0}{\pi}}$ & & & & & & & \\
\hline Anderson ${ }^{73}$ & 2007 & 23 & Visual & $\begin{array}{l}\text { GTV } \\
\text { PTV }\end{array}$ & volume/overlap tumour & & $x$ & & & $x$ & & \\
\hline Krengli 90 & 2010 & 27 & $\mathrm{SUV} \geq 40 \% \mathrm{SUV}_{\max }$ & $\begin{array}{l}\text { GTV } \\
\text { CTV }\end{array}$ & volume tumour + LN & & $x$ & & & $x$ & & \\
\hline Rusten ${ }^{91}$ & 2017 & 19 & Visual & GTV & volume tumour & & & & & $x$ & & \\
\hline Nguyen ${ }^{92}$ & 2008 & 50 & Visual & GTV & LN involvement & & & $x$ & & & & $x$ \\
\hline de Winton ${ }^{93}$ & 2009 & 61 & Visual & GTV & LN involvement & & $x$ & $x$ & & & & $x$ \\
\hline Mai $^{94}$ & 2009 & 39 & SUV $\geq 2.5$ & GTV & LN involvement & & & $x$ & & & & $x$ \\
\hline Bannas ${ }^{95}$ & 2011 & 22 & Visual & GTV & LN involvement & & $x$ & $x$ & & & & \\
\hline Mistrangelo ${ }^{96}$ & 2012 & 53 & Not described & GTV & LN involvement & & & $x$ & & & & $x$ \\
\hline $\begin{array}{l}\text { Zimmermann } \\
97\end{array}$ & 2017 & 26 & Visual (liver SBR) & GTV & LN involvement & & $x$ & & & & & $x$ \\
\hline Liang 98 & 2013 & 12 & $\begin{array}{l}\text { SUV }>\text { SUV } V_{\text {mean }} \text { (SUV corrected for body } \\
\text { weight) \& fat fraction }<\text { mean on IDEAL IQ } \\
\text { MRI }\end{array}$ & OAR & $\begin{array}{l}\text { sparing of functional bone } \\
\text { marrow }\end{array}$ & & $x$ & & & & & \\
\hline Franco $^{99}$ & 2017 & 10 & $\begin{array}{l}\text { SUV > SUV } \\
\text { weight) }\end{array}$ & OAR & $\begin{array}{l}\text { sparing of functional bone } \\
\text { marrow }\end{array}$ & & $x$ & & & & & \\
\hline Rose ${ }^{100}$ & 2016 & 45 & $\begin{array}{l}\text { SUV > SUV } \\
\text { weight) }\end{array}$ & OAR & $\begin{array}{l}\text { sparing of functional bone } \\
\text { marrow }\end{array}$ & & $x$ & & & & & $x$ \\
\hline
\end{tabular}




\section{APPENDIX 1: RESEARCH STRATEGY}

Concept 1: Patients with

- oesophageal cancer

"Esophageal Neoplasms"[Mesh] OR Esophageal Neoplasm*[tiab] OR Esophagus Neoplasm*[tiab] OR Cancer of the Esophagus[tiab] OR Esophagus Cancer*[tiab] OR Esophageal Cancer*[tiab] OR Esophageal Tumor*[tiab] OR Esophagus Tumor*[tiab] OR Tumor of the Esophagus[tiab] OR Tumors of the Esophagus[tiab] OR Esophageal Tumour*[tiab] OR Esophagus Tumour*[tiab] OR Tumour of the Esophagus[tiab] OR Tumours of the Esophagus[tiab] OR Oesophageal Neoplasm*[tiab] OR Oesophagus Neoplasm*[tiab] OR Cancer of the Oesophagus[tiab] OR Oesophagus Cancer*[tiab] OR Oesophageal Cancer*[tiab] OR Oesophageal Tumor*[tiab] OR Oesophagus Tumor*[tiab] OR Tumor of the Oesophagus[tiab] OR Tumors of the Oesophagus[tiab] OR Oesophageal Tumour*[tiab] OR Oesophagus Tumour*[tiab] OR Tumour of the Oesophagus[tiab] OR Tumours of the Oesophagus[tiab]

- stomach cancer

"Stomach Neoplasms"[Mesh] OR Stomach Neoplasm*[tiab] OR Gastric Neoplasm*[tiab] OR Cancer of the Stomach[tiab] OR Stomach Cancer*[tiab] OR Gastric Cancer*[tiab] OR Stomach Tumor*[tiab] OR Gastric Tumor*[tiab] OR Tumor of the Stomach[tiab] OR Tumors of the Stomach[tiab] OR Stomach Tumour*[tiab] OR Gastric Tumour*[tiab] OR Tumour of the Stomach[tiab] OR Tumours of the Stomach[tiab]

- pancreatic cancer

"Pancreatic Neoplasms"[Mesh] OR Pancreatic Neoplasm*[tiab] OR Pancreas Neoplasm*[tiab] OR Cancer of the Pancreas[tiab] OR Pancreas Cancer*[tiab] OR Pancreatic 
Cancer*[tiab] OR Pancreas Tumor*[tiab] OR Pancreatic Tumor*[tiab] OR Tumor of the Pancreas[tiab] OR Tumors of the Pancreas[tiab] OR Pancreas Tumour*[tiab] OR Pancreatic Tumour*[tiab] OR Tumour of the Pancreas[tiab] OR Tumours of the Pancreas[tiab]

- biliary tract cancer

"Biliary Tract Neoplasms"[Mesh] OR Biliary Tract Neoplasm*[tiab] OR Cancer of the Biliary tract[tiab] OR Biliary Tract Cancer*[tiab] OR Biliary Tract Tumor*[tiab] OR Tumor of the Biliary Tract[tiab] OR Tumors of the Biliary Tract[tiab] OR Biliary Tract Tumour*[tiab] OR Tumour of the Biliary Tract[tiab] OR Tumours of the Biliary Tract[tiab] OR Bile Duct Neoplasm*[tiab] OR Cancer of the Bile Duct[tiab] OR Bile Duct Cancer*[tiab] OR Bile Duct Tumor*[tiab] OR Tumor of the Bile Duct[tiab] OR Tumors of the Bile Duct[tiab] OR Bile Duct Tumour*[tiab] OR Tumour of the Bile Duct[tiab] OR Tumours of the Bile Duct[tiab] OR Gallbladder Neoplasm*[tiab] OR Cancer of the Gallbladder[tiab] OR Gallbladder Cancer*[tiab] OR Gallbladder Tumor*[tiab] OR Tumor of the Gallbladder[tiab] OR Tumors of the Gallbladder[tiab] OR Gallbladder Tumour*[tiab] OR Tumour of the Gallbladder[tiab] OR Tumours of the Gallbladder[tiab] OR Gall Bladder Neoplasm*[tiab] OR Cancer of the Gall Bladder[tiab] OR Gall Bladder Cancer*[tiab] OR Gall Bladder Tumor*[tiab] OR Tumor of the Gall Bladder[tiab] OR Tumors of the Gall Bladder[tiab] OR Gall Bladder Tumour*[tiab] OR Tumour of the Gall Bladder[tiab] OR Tumours of the Gall Bladder[tiab]

- liver cancer

"Liver Neoplasms"[Mesh] OR Liver Neoplasm*[tiab] OR Hepatic Neoplasm*[tiab] OR Cancer of the Liver[tiab] OR Hepatocellular Cancer*[tiab] OR Hepatic Cancer*[tiab] OR Liver Cancer*[tiab] OR Liver Tumor*[tiab] OR Hepatic Tumor*[tiab] OR Hepatocellular Tumor*[tiab] OR Tumor of the Liver[tiab] OR Tumors of the Liver[tiab] OR Liver 
Tumour*[tiab] OR Hepatic Tumour*[tiab] OR Hepatocellular Tumour*[tiab] OR Tumour of the Liver[tiab] OR Tumours of the Liver[tiab]

- cancer of the large bowel

"Colon Neoplasms"[Mesh] OR Colon Neoplasm*[tiab] OR Colonic Neoplasm*[tiab] OR Large Bowel Neoplasm*[tiab] OR Cancer of the Colon[tiab] OR Cancer of the Large Bowel [tiab] OR Colon Cancer*[tiab] OR Colonic Cancer*[tiab] OR Large Bowel Cancer*[tiab] OR Colon Tumor*[tiab] OR Colonic Tumor*[tiab] OR Large Bowel Tumor*[tiab] OR Tumor of the Colon[tiab] OR Tumor of the Large Bowel[tiab] OR Tumors of the Colon[tiab] OR Tumors of the Large Bowel[tiab] OR Colon Tumour*[tiab] OR Colonic Tumour*[tiab] OR Large Bowel Tumour*[tiab] OR Tumour of the Colon[tiab] OR Tumour of the Large Bowel[tiab] OR Tumours of the Colon[tiab] OR Tumours of the Large Bowel[tiab]

- rectal cancer

"Rectal Neoplasms"[Mesh] OR Rectal Neoplasm*[tiab] OR Rectum Neoplasm*[tiab] OR Cancer of the Rectum[tiab] OR Rectal Cancer*[tiab] OR Rectum Cancer*[tiab] OR Rectal Tumor*[tiab] OR Rectum Tumor*[tiab] OR Tumor of the Rectum[tiab] OR Tumors of the Rectum[tiab] OR Rectal Tumour*[tiab] OR Rectum Tumour*[tiab] OR Tumour of the Rectum[tiab] OR Tumours of the Rectum[tiab]

- anal cancer

"Anus Neoplasms"[Mesh] OR Anus Neoplasm*[tiab] OR Anal Neoplasm*[tiab] OR Cancer of the Anus[tiab] OR Anus Cancer*[tiab] OR Anal Cancer*[tiab] OR Anus Tumor*[tiab] OR Anal Tumor*[tiab] OR Tumor of the Anus[tiab] OR Tumors of the Anus[tiab] OR Anus Tumour*[tiab] OR Anal Tumour*[tiab] OR Tumour of the Anus[tiab] OR Tumours of the Anus[tiab] 
AND

Concept 2: radiotherapy

"Radiotherapy"[Mesh] OR Radiotherap*[tiab] OR Radiation Therap*[tiab] OR Brachytherap*[tiab] OR Curietherap*[tiab] OR Chemoradiotherap*[tiab] OR Radiochemotherap*[tiab] OR Chemoradiation[tiab] OR "Radiation, Ionizing"[Mesh] OR Ionizing Radiation*[tiab] OR lonising Radiation*[tiab] OR Irradiation[tiab]

AND

Concept 3: PET

"Tomography, Emission-Computed"[Mesh:NoExp] OR Emission-Computed Tomography[tiab] OR "Positron-Emission Tomography"[Mesh] OR Positron-Emission Tomography[tiab] OR PET[tiab] 